\title{
Conditioned inhibition training of the competing cue after compound conditioning does not reduce cue competition
}

\author{
ANTHONY S. RAUHUT, JANICE E. MCPHEE, NORMA T. DiPIETRO, and JOHN J. B. AYRES \\ University of Massachusetts, Amherst, Massachusetts
}

\begin{abstract}
In each of two experiments, we studied Pavlovian fear conditioning (as assessed by barpress conditioned suppression ) in 32 albino rats. Following a two-stage cue-competition procedure $(A+$ then $A X+)$, we subjected the competing cue (A) to conditioned inhibition training $(\mathrm{B}+, \mathrm{BA}-)$ before testing the target cue $(\mathrm{X})$. Conditioned inhibition training was designed to weaken the putative A-unconditioned stimulus (US) association, perhaps changing it to an A-no-US association. Performance-deficit theories of cue competition, such as comparator theory and retrieval-interference theory, predict that such procedures should weaken cue competition, causing Conditioned Stimulus X (CS X) to evoke strong responding. The same prediction can be deduced from recent acquisition-focused models (Dickinson \& Burke, 1996; Van Hamme \& Wasserman, 1994). In opposition to this prediction, however, we found in both experiments that conditioned inhibition training had no detectable effect on cue competition even though it successfully abolished conditioned responding to CS A. In Experiment 2, moreover, we found evidence against the hypothesis that the weak response to CS X was due to generalization decrement rather than to cue competition. Results favor early learning-deficit theories of cue competition over performance-deficit theories and over the recent acquisition-focused models.
\end{abstract}

In a blocking paradigm, Conditioned Stimulus X (CS X) is reinforced in compound with CS A and is later tested in isolation. The result is that $\mathrm{X}$ evokes weaker responding if $A$ had previously been conditioned than if it had not. Conditioned performance to $\mathrm{X}$ is said to have been "blocked" by the prior conditioning of A (Kamin, 1968). In an overshadowing paradigm, CS X is reinforced and is later tested in isolation. The result is that $\mathrm{X}$ evokes weaker responding if its reinforcement had occurred in the presence of a previously untrained CS (A) than if its reinforcement had occurred in isolation. Conditioned performance to $\mathrm{X}$ is said to have been "overshadowed" by CS A (Pavlov, 1927). Blocking and overshadowing are both examples of cue competition. In each paradigm, conditioning to one cue $(\mathrm{A})$ competes with or detracts from conditioned performance to a second cue (X).

Early theories of cue competition assumed that it reflected deficits in learning that occurred at the time of

Support for this work came from National Institutes of Mental Health Grants MH50491 and MH57459 and a faculty research grant from the University of Massachusetts, Amherst awarded to J. J. B. Ayres. A. S. Rauhut was supported by Predoctoral Fellowship MH11932-01 from the National Institutes of Mental Health. Any opinions, findings, conclusions, or recommendations expressed are those of the authors and do not necessarily reflect the views of the granting agencies. Experiment 1 was described at the 69th meeting of the Eastern Psychological Association, March 1998 by A. S. Rauhut. The authors thank John W. Moore for suggesting the use of the conditioned inhibition procedure as a means of reducing the A-US association. Correspondence should be addressed to J. J. B. Ayres, Department of Psychology, University of Massachusetts, Amherst, MA 01003 (e-mail: joeayres@psych.umass.edu). reinforcement (Kamin, 1968; Mackintosh, 1975; Pearce \& Hall, 1980; Rescorla \& Wagner, 1972; Wagner, 1981). They assumed that the effects reflected the ability of CS A to prevent the formation of a strong $\mathrm{X}$-unconditioned stimulus (US) association. More recently, however, theorists have proposed that cue competition reflects deficits occurring not at the time of reinforcement but rather at the time of testing. Thus, CS A does not affect the formation of the $\mathrm{X}$-US association. Rather, it prevents that association from generating behavior when $\mathrm{X}$ is tested alone (e.g., Miller \& Grahame, 1991). This theory is termed performance-deficit theory in contrast to the earlier learning-deficit theories.

There are two major variants of the performance-deficit view: comparator theory and retrieval-interference theory. According to comparator theory (Miller \& Schachtman, 1985), when $A$ and $X$ are reinforced in compound, each becomes associated with the US, just as if the other were not there, and each becomes associated with the other. The consequence of this within-compound association is that when $X$ is tested alone, it evokes both a representation of the US and a representation of $A$, which, in turn, evokes a representation of the US that had been paired with $\mathrm{A}$. The theory postulates that responding to $\mathrm{X}$ varies directly with the strength of the $\mathrm{X}$-US association and inversely with the product of the $\mathrm{X}-\mathrm{A}$ and $\mathrm{A}-\mathrm{US}$ associations (Blaisdell, Gunther, \& Miller, 1999, p. 64).

Like comparator theory, retrieval-interference theory (Balaz, Gutsin, Cacheiro, \& Miller, 1982; Kasprow, Cacheiro, Balaz, \& Miller, 1982) also assumes that the $\mathrm{X}$-US association is strong when $\mathrm{X}$ is tested alone after 
being reinforced in A's presence; however, this association fails to yield performance. The reason is that some other strong association, such as the A-US association, interferes with retrieval of the X-US association. If the $\mathrm{X}$-US association is not retrieved to working memory, it cannot be expressed in behavior.

Evidence for both retrieval-interference theory and comparator theory has come from experiments that subjected CS A to extinction following training of the AX compound (e.g., Blaisdell et al., 1999; Cole, Barnet, \& Miller, 1995; Harris \& Westbrook, 1998; Kaufman \& Bolles, 1981; Matzel, Schachtman, \& Miller, 1985; Matzel, Shuster, \& Miller, 1987; Yin, Grahame, \& Miller, 1993). Such extinction should weaken X's comparator, A-US, association according to comparator theory and should weaken the source of retrieval interference according to retrieval-interference theory. These studies have found that such extinction of A did indeed enhance responding to $\mathrm{X}$ as predicted, an effect that is often termed retrospective revaluation. This term implies that, at the time of testing, the animal assigns a new, inflated, value to $\mathrm{CS} \mathrm{X}$ because the value of its companion, CS A, has been deflated by the A-extinction trials that followed $\mathrm{AX}$ training. A more neutral term for the phenomenon is recovery from cue competition. This term merely describes a result, without implying anything about underlying psychological processes.

Recently, acquisition-focused models have been developed to predict and explain recovery from cue competition in a molecular, trial-by-trial manner (Dickinson \& Burke, 1996; Van Hamme \& Wasserman, 1994). The first of these (Van Hamme \& Wasserman, 1994) did so by revising Rescorla and Wagner's (1972) model to allow a CS's value to change on trials when the CS itself was not presented. As is well known, the basic Rescorla-Wagner $(\mathrm{R}-\mathrm{W})$ rule states that

$$
\Delta V_{\mathrm{X}}=\alpha_{\mathrm{X}} * \beta(\lambda-\Sigma V) .
$$

Here, $\Delta V_{\mathrm{X}}$ represents the change in CS X's associative value as a result of a trial on which it is presented. The quantities $\alpha \mathrm{X}$ and $\beta$ are parameters whose values lie between 0 and 1 and that represent the saliences or the associabilities of CS X and the US, respectively. Importantly, $\alpha_{\mathrm{X}}$ is always 0 on trials in which CS X is absent. In contrast, $\beta$, though smaller on nonreinforced trials than on reinforced trials, is always assigned a value greater than zero. $\lambda$ represents the asymptotic associative value attainable with the US in question. It is set equal to 0 on nonreinforced trials and to a value greater than 0 on reinforced trials. $\Sigma V$ represents the sum of the associative values of all stimuli present on the trial.

Van Hamme and Wasserman (1994) offered a revised $\mathrm{R}-\mathrm{W}$ rule, in which $\alpha_{\mathrm{X}}$ would take on negative values on trials on which $\mathrm{X}$ was not presented but its withincompound associate, $\mathrm{A}$, was. In this case, $\alpha_{\mathrm{X}}$ might be thought of as reflecting the salience of the $X$ representation evoked by its within-compound associate, $\mathrm{A}$ (for discussion see, Wasserman \& Berglan, 1998). According to the revised $\mathrm{R}-\mathrm{W}$ rule, each $\mathrm{A}-$ trial that followed a series of $\mathrm{AX}+$ trials would allow CS X to gain an increment in value because the product of the negative $\alpha_{X}$ and the negative quantity in parentheses would be positive. In summary, this theory agrees with the early learningdeficit theories that cue competition results in a learning deficit to the target cue; but, unlike the early theories, it allows for recovery from cue competition.

The second of the acquisition-focused models that predicts recovery from cue competition has been offered by Dickinson and Burke (1996). It is a revision of Wagner's (1981) sometimes opponent process (SOP) theory. In the SOP theory, stimuli are represented as elements that exist in separate memory nodes. Each stimulus node consists of three states: an inactive memory state (I), a working memory state (A1), and a state (A2) partway between A1 and I. During each moment that a stimulus is exposed, a fraction of elements in its I state shifts to A1. During each subsequent moment, a fraction of the elements in A1 decays to A2; during each subsequent moment after that, a fraction of the elements in $A 2$ begins to decay back to $I$. The rate of decay from $A 2$ is slower than the rate of decay from A1. The tendency for stimuli to become associated with one another is proportional to the number of elements concurrently in their A1 states. Once a CS has become associated with a US, it can activate elements in the US node directly from the I state to the A2 state. Cue competition occurs because the competing cue directly activates US elements to the A2 state. This leaves fewer US elements available in I to be promoted to Al by the US when the target cue's elements are concurrently in Al. Thus, the association between the target cue and the US is limited; the target suffers a learning deficit. To explain recovery from cue competition, Dickinson and Burke suggested that stimuli might become associated not only when their elements were concurrently in their A1 states but also when they were concurrently in their A2 states. Thus, when A- trials follow AX+trials, A would promote US elements and X elements from their I to their A2 states. This conjunction of $\mathrm{X}$ and US elements in A2 would strengthen the X-US association, allowing $X$ to recover from cue competition.

Although both the revised $\mathrm{R}-\mathrm{W}$ rule and the revised SOP theory predict recovery from cue competition, we should note that, quite often in animal conditioning, such recovery is not found (Kamin, 1968; Rauhut, McPhee, \& Ayres, 1999; Revusky, Parker, \& Coombes, 1977; Schachtman, Kasprow, Meyer, Bourne, \& Hart, 1992, Experiments 1, 2, and 3). Indeed, just as often, the results are quite the opposite: Extinction of A weakens responding to X (Couvillon \& Bitterman, 1982; Holland \& Ross, 1981; Rescorla \& Colwill, 1983; Schachtman et al., 1992, Experiments 4 and 5; Schweitzer \& Green, 1982; Speers, Gillan, \& Rescorla, 1980).

One recent study that found that extinguishing CS A failed to restore responding to CS X was that of Rauhut et al. (1999). These authors extinguished CS A following two different cue-competition procedures. In their 
Experiment 4, they used 32 extinction exposures of a 2min CS A; in their Experiment 5, they used 102 such exposures. A possible criticism of their work was that they failed to give enough exposures in their Experiment 4 (cf. Blaisdell et al., 1999). And, although they gave many more exposures in their Experiment 5, they found substantial spontaneous recovery of responding to CS A in at least the first four of their six extinction sessions. The prevalence of such spontaneous recovery casts doubt on the extent to which they succeeded in extinguishing the A-US association. Further doubt was cast in a final test of A that was performed after tests of other CSs. In that final test, CS A again evoked moderately strong performance.

In Experiment 1 of the present research, we attempted a technique that, theoretically, should be more effective than simple extinction at weakening the A-US association; indeed, the technique might even reverse that association, changing it to an A-no-US association. The technique was Pavlovian conditioned inhibition training of the form $\mathrm{B}+, \mathrm{BA}-$. That training also included intermingled nonreinforced exposures of $A$ in isolation. Such exposures are known not to weaken conditioned inhibition (Witcher \& Ayres, 1984; Zimmer-Hart \& Rescorla, 1974) and may even strengthen it (DeVito \& Fowler, $1986,1987)$. Strong responding to CS B coupled with weak responding to the BA compound and to $\mathrm{A}$ in isolation would be consistent with the idea that $A$ had been changed to a conditioned inhibitor or at least with the idea that the A-US association had been substantially reduced or substantially opposed by a competing A-no-US association. This conclusion could then be further strengthened if, after tests of CS X were completed, a test of A showed no recovery of excitatory responding.

Besides weakening the A-US association, the conditioned inhibition procedure should have a second consequence of importance to comparator theory. When CS A is exposed in the absence of CS X, a weakening of the $\mathrm{X}-\mathrm{A}$ within-compound association is expected (Rescorla \& Freberg, 1978). Rauhut et al. (1999) presented A in X's absence in only one way: They exposed A in isolation. In the present experiments, we presented A in X's absence in two ways: in isolation and in compound with CS B. It is not unreasonable to believe that the more ways that $A$ is presented in X's absence, the weaker the $\mathrm{X}$-A within-compound association should become. According to comparator theory, excitatory responding to $\mathrm{X}$ is inversely related to the product of the $\mathrm{X}-\mathrm{A}$ and $\mathrm{A}-\mathrm{US}$ associations. Our conditioned inhibition procedure should excel at reducing both of these associations; therefore, it should be especially effective in fostering the expression of the X-US association.

Conditioned inhibition training of CS A should also be especially effective in fostering recovery from cue competition according to the revised $\mathrm{R}-\mathrm{W}$ rule. For example, if we compare the effects of an $A-$ trial with those of a BA - trial in which $B$ has previously been conditioned to asymptote, we can see that the quantity in parentheses of Equation 1 is much more negative in the BA- case. Given the negative $\alpha \mathrm{X}$, this means that the positive increment to X must be greater than on a corresponding Atrial. The revised SOP theory makes a similar prediction, given its new assumption that CS X and the US become associated when both have elements concurrently in A2. The reason is that on BA- trials, CS A will promote $\mathrm{CS} \mathrm{X}$ elements from I to A2 and, at first, will also promote US elements from I to A2. CS B, whose conditioned strength is always maintained throughout the $\mathrm{B}+$, $B A$ - procedure, will always promote US elements from I to A2. The number of US elements in A2 will always be larger on BA - trials than on A- trials. Therefore, the association between $X$ and the US will grow stronger on $\mathrm{BA}$ - trials than on A- trials.

In Experiment 2, we sought to replicate the main findings of Experiment 1 . We also included a control group designed to see whether the effects that we attributed to cue competition were instead due to generalization decrement. In addition, after the $\mathrm{B}+, \mathrm{BA}-$ procedure, we performed a transfer-summation test and a retardation test (Rescorla, 1969) in search of evidence that CS A did indeed become inhibitory.

As in much past work on cue competition, we used the conditioned suppression procedure (Estes \& Skinner, 1941) to index conditioned performance. We paired our CSs with shock USs while our rat subjects barpressed for food. We took the amount of barpress suppression evoked by the CSs as a measure of the strength of the conditioned response (CR). Suppression occurs because the rat crouches and remains immobile, usually away from the bar, when frightened by the CS (Bevins \& Ayres, 1992, 1994; Bouton \& Bolles, 1980; Mast, Blanchard, \& Blanchard, 1982). That behavior is incompatible with barpressing.

\section{EXPERIMENT 1}

\section{Method}

Subjects. The subjects were 32 male albino rats of Holtzman stock bred at the University of Massachusetts, Amherst. At the start of deprivation, they were about 90 days old and ranged in weight from 337 to $620 \mathrm{~g}$. All rats were housed singly in stainless steel mesh cages with free access to water. The colony was lighted from 0700 to $2300 \mathrm{~h}$ daily, and the experiment was performed between 0900 and $1700 \mathrm{~h}$. Beginning 7 days before the experiment, each rat was handled for $1 \mathrm{~min}$ each day and was fed only 3-5 g daily to reduce it to $80 \%$ of its free-feeding weight. All rats were kept at this level throughout the study.

Apparatus. Eight operant boxes (inside dimensions $=23.2 \times$ $20.3 \times 19.5 \mathrm{~cm}$ ) were housed in $0.61-\mathrm{m}$ ventilated cubes of $12.7-$ $\mathrm{mm}$-thick plywood, lined with acoustical tile. The end walls of each box were aluminum; the sides and top were clear Plexiglas. Centered in one end wall was a response bar $(5 \times 1.5 \mathrm{~cm})$ mounted $8 \mathrm{~cm}$ above the floor. A dipper tray $(5 \times 5 \times 5.5 \mathrm{~cm})$ was recessed in the lower left corner of this same wall. The floor consisted of 18 stainless steel rods ( $2 \mathrm{~mm}$ in diameter), centers spaced $1.3 \mathrm{~cm}$ apart. A shock US ( $0.8 \mathrm{~mA}, 1 \mathrm{sec})$ produced by 8 Grason-Stadler shock generators and scramblers (Models E1064 and 700) was delivered through these rods. 
Four CSs (A, B, C, and X) were produced as follows. Two speakers $(10 \mathrm{~cm}$ in diameter) were mounted on each box lid. One speaker provided a continuous white noise of $80 \mathrm{~dB}$ when added to the noise produced by the ventilation fans. The cessation of the white noise, leaving a background of $68 \mathrm{~dB}$, served as CS A. The other speaker produced a tone $(1000 \mathrm{~Hz}, 86 \mathrm{~dB})$ that served as CS B. CS C was a series of clicks produced by the $10-\mathrm{Hz}$ operation of a relay (KHP17D11, Potter \& Brumfield), which was bolted through its plastic casing to the outer surface of the Plexiglas wall to the rat's right as it faced the response bar. The clicks raised the sound level to $86 \mathrm{~dB}$. Sound intensity was measured using a sound level meter (Radio Shack \#33-2050, Slow-C) with the microphone placed about $7 \mathrm{~cm}$ from the dipper tray. The illumination of a frosted white light bulb ( $120 \mathrm{~V}, 7.5 \mathrm{~W})$ served as CS X. This bulb was mounted on the back wall of the ventilated cube (to the rat's right as it faced the bar), just above a constantly lit red bulb ( $120 \mathrm{~V}, 7.5 \mathrm{~W})$. Each $\mathrm{CS}$ was always $2 \mathrm{~min}$ in duration.

Barpressing was reinforced by a 4-sec access to a $0.1-\mathrm{ml}$ dipper cup of $32 \%$ liquid sucrose. A computer in an adjacent room controlled all programmed events and recorded the number of barpresses in each minute of each session.

Procedure. The procedure is outlined in Table 1. The rats were randomly assigned to four groups $(n \mathrm{~s}=8)$ : $\mathrm{CC} \_\mathrm{CI}, \mathrm{NC} \_\mathrm{CI}, \mathrm{CC} \_\mathrm{NI}$, and NC_NI. Here, the term before the dash (_) denotes whether the group underwent a cue-competition procedure (CC) or no competition (NC). The term after the dash denotes whether the group later received conditioned inhibition training $(\mathrm{CI})$ to $\mathrm{CS}$ A or no inhibition training (NI). Following preliminary barpress training (not shown in the table), Stage 1 consisted of acquisition to CSs $A$ and B for all groups. In Stage 2, Groups CC_CI and CC_NI received training to the stimulus compound $\mathrm{AX} ; \mathrm{CS} \mathrm{A}$ was intended to compete with X. Groups NC_CI and NC_NI received training to CS X alone; thus, there was no $C S$ to compete with $X .^{1}$ In Stage 3, Groups CC_CI and $\mathrm{NC} \_$CI received conditioned inhibition training designed to reduce A's excitation and perhaps to convert it to inhibition. Thus, these groups received reinforced exposures to $\mathrm{CS} B(\mathrm{~B}+$ trials) and nonreinforced exposures to the BA compound (BA- trials). They also received numerous nonreinforced exposures to CS A in isolation (A - trials) so that A's effects could be assessed independently of $B$ and so that any excitation to A resulting from its association with $B$ in the BA compound could be weakened. In contrast, Groups $\mathrm{CC}_{-} \mathrm{NI}$ and NC_NI received the same $\mathrm{B}+$ trials as the conditioned inhibition groups but received $\mathrm{C}$ - trials instead of $\mathrm{BA}-$ trials. In addition, they received only two A- trials so that A's effects could be assessed in the absence of other cues but without seriously weakening A's conditioned value. In Stage 4, all groups underwent extinction testing to CS X alone so as to assess cue competition. In Stage 5, all groups received a brief test of CS A, allowing us to see whether any spontaneous recovery occurred in the groups that had received conditioned inhibition training to A.

Preliminary training. Preliminary training included 2 days of teaching the rats to approach the dipper when raised (magazine training), 3 days of teaching them to barpress for sucrose with each barpress reinforced (CRF schedule), 2 days of training in which food could be earned at variable intervals averaging $60 \mathrm{sec}$ (VI 60 -

Table 1

Design of Experiment 1

\begin{tabular}{llllll}
\hline Group & Stage 1 & Stage 2 & Stage 3 & Test & Test \\
\hline CC_CI & A+,B+ & AX+ & B,$+ B A-$ & X- & A- \\
CC_NI & A+,B+ & AX+ & B,+ C - & X- & A- \\
NC_CI & A,$+ B+$ & X+ & B,$+ B A-$ & X- & A- \\
NC_NI & A+,B + & X+ & B+,C- & X- & A- \\
\hline
\end{tabular}

Note $-\mathrm{CS} \mathrm{A}=$ noise off; $\mathrm{CS} \mathrm{B}=$ tone; $\mathrm{CS} \mathrm{C}=$ click; CS X $=$ light. The "+" sign indicates that a CS was paired with a shock (US). The "-" sign indicates a CS was not paired with a US. sec schedule of reinforcement), and 3 days of pretesting CSs A, B, $C$, and X. Each CS was given once daily. On Days 1 and 3 of pretesting, the order was B, C, X, A. On Day 2, the order was reversed. Throughout the experiment, all CSs were $2 \mathrm{~min}$ in duration. Beginning with VI training, each session was $60 \mathrm{~min}$ long, and the VI schedule remained in force in every session for every group.

Stage $1(A+$ and $B+$ training). Stage 1 lasted 6 days. On each day, each group received one $\mathrm{A}+$ trial and one $\mathrm{B}+$ trial. The goal was to establish CS A as an excitor to maximize its later competition with $\mathrm{CS} \mathrm{X}$ and to establish CS B as an excitor in whose presence CS A could later be nonreinforced in a Pavlovian conditioned inhibition procedure $\left(\mathrm{B}^{+}, \mathrm{BA}-\right)$. This procedure should weaken $\mathrm{A}^{\prime}$ ' excitation and perhaps change it to inhibition. Throughout this research, when trials were reinforced, shock was delivered in the last $1 \mathrm{sec}$ of the 2-min CS.

Stage $2(A X+$ or $X+$ training). On each of 6 days in Stage 2, Groups $\mathrm{CC}_{-} \mathrm{CI}$ and $\mathrm{CC}_{-} \mathrm{NI}$ received two $\mathrm{AX}+$ trials, whereas Groups NC_CI and NC_NI received two $\mathrm{X}+$ trials. The aim was for CS A to compete with $\mathrm{X}$ only in the two CC groups. On Day 5 of this stage, all groups received one $\mathrm{X}$ - "probe" trial in addition to their typical treatment. The goal was to provide evidence (before conditioned inhibition training) of cue competition in Groups CC_CI and CC_NI. Weaker suppression to CS X in these two groups relative to the other two groups would suggest that $\mathrm{CS}$ A successfully competed with $\mathrm{CS} X$ in Groups CC_CI and CC_NI.

Stage 3 (conditioned inhibition training). Stage 3 lasted 24 days. On each day, the two groups that received conditioned inhibition training, Groups $\mathrm{CC}_{-} \mathrm{CI}$ and NC_CI, received either two $\mathrm{B}+$ and two $\mathrm{BA}-$ trials (Days 6, 10, 15, 18, 19,21, and 23) or one $\mathrm{B}+$ and three $\mathrm{BA}-$ trials (remaining days). This $\mathrm{B}+, \mathrm{BA}-$ procedure was intended to weaken the excitatory value of $C S A$, perhaps converting $\mathrm{A}$ into a conditioned inhibitor of fear. Group CC_CI also received one A- trial on Days 11-24. This procedure had three aims. First, it was intended to assess the conditioned strength of CS A independently of CS B. Second, it was intended to weaken any excitation that A might gain by being associated with $\mathrm{B}$. Third, it, together with the BA- trials, was intended to weaken the $\mathrm{X}-\mathrm{A}$ association. Altogether, the two groups that received B+, BA-training experienced a total of 792 -min nonreinforced exposures to CS A, either alone or in compound with CS B, for a total of $158 \mathrm{~min}$ of nonreinforced exposure. The two groups that received no conditioned inhibition training to CS A, Groups CC_NI and NC_NI, received during this stage the same daily number of $\mathrm{B}+$ trials and nonreinforced trials as the other two groups. However, CS $C$ replaced both the BA- trials and the A-trials, with one exception: On Days 11 and $24, \mathrm{CS} A$ was presented once to these two groups. The aim was to assess the conditioned value of CS A apart from CS B, while minimizing the extinction of that value.

Stage 4 (extinction test to $\mathrm{X}$ ). Stage 4 , the critical test of CS X, lasted 3 days. Each group received two $X-$ trials per day. Weaker suppression to CS X in Groups CC_CI and CC_NI than in the other two groups would suggest that CS A successfully competed with conditioned performance to CS X. Weaker suppression in CC_NI than in CC_CI would suggest that weakening the excitation conditioned to $\mathrm{CS} A$ and/or weakening the $\mathrm{X}-\mathrm{A}$ association in Group CC_CI reduced the potential of CS A to compete with CS X. Comparator theory expects such a reduction because weakening the A-US association weakens the product of the X-A and A-US associations, allowing the $\mathrm{X}-\mathrm{US}$ association to be expressed. Retrieval-interference theory expects the same result, because weakening the A-US association should reduce its ability to interfere with retrieval of the X-US association during the test of X's effects. The revised R-W rule and the revised SOP theory expect the effect, because each exposure to A- should cause an increase in the associative value of its within-compound associate, $\mathrm{X}$; moreover, this increase should be especially pronounced when $A$ is nonreinforced in compound with an excitor such as CS B. 
Stage 5 (extinction test to A). A one-trial extinction test of A's effects was given in Stage 5. Any conditioned suppression evoked by CS A would suggest that the conditioned inhibition procedure had been less than successful at weakening the A-US association or at holding it in check with a CS-no-US association.

Measure of conditioning. CS-evoked suppression of barpressing was expressed in terms of a suppression ratio, $D /(D+B)$. Here, $D$ is the number of responses occurring during a $2-\mathrm{min} \mathrm{CS}$, and $B$ is the number of responses in the 2 min just before the CS (Annau \& Kamin, 1961). A ratio of 0 denotes strong suppression, and a ratio of .5 denotes no effect of the CS. Rarely, a suppression ratio could not be computed because a rat stopped responding during both the $\mathrm{CS}$ and the pre-CS periods. On such a trial, we estimated the suppression ratio by averaging the ratios obtained on the immediately preceding trial and the immediately following trial. ${ }^{2}$

Statistical analyses. Most results were analyzed using mixeddesign analyses of variance (ANOVAs) followed in some cases by planned contrasts, using $t$ tests. The error term and degrees of freedom for those tests were derived from the ANOVA (Winer, 1962, chap. 7). A two-tailed critical region of .05 was used throughout.

\section{Results}

The main result of Experiment 1 was that subjecting CS A to Pavlovian conditioned inhibition training, after $\mathrm{AX}+$ training and before testing of $\mathrm{CS} \mathrm{X}$, failed to reduce cue competition in Group CC_CI. This group showed weaker suppression than either of the two control groups and did not differ from Group CC_NI. Group CC_NI had also received a cue-competition treatment but had not received Pavlovian conditioned inhibition training.

Stage 1 (A+ and B+). One rat in Group NC_NI failed to condition to CS B (suppression ratio averaged over all six trials $>.40$ ). This rat was removed from the study, and degrees of freedom were reduced accordingly. Except for this rat, suppression to CS A and to CS B was acquired normally. For CS A, the mean suppression ratio dropped from .48 on Trial 1 to .01 on Trial 6. For CS B, the mean suppression ratio dropped from .50 on Trial 1 to .03 on
Trial 6. Consistent with their not having been treated differently at this point, the groups did not differ in their suppression. Group $\times$ trial ANOVAs conducted separately on the suppression to CS A and to CS B revealed only the effect of trial to be significant $\left[F_{\mathrm{S}}(5,135)>114\right]$.

Stage $2(\mathbf{A X}+\mathbf{v s .} \mathbf{X}+)$. The results of Stage 2, excluding the probe trial, are shown in Figure 1. Because of their prior training to CS A, Groups CC_CI and CC_NI suppressed strongly to the $\mathrm{AX}$ compound from the outset of this stage. In contrast, Groups NC_CI and NC_NI both gradually acquired suppression to the previously untrained CS X. A group $\times$ trial ANOVA isolating these latter two groups revealed only a significant effect of trial $[F(11,143)=23.39]$, implying that the two groups did not differ in their rates of acquisition to CS X.

Figure 2 (top panel) shows the results of the probe trial given on Day 5 of Stage 2. A two-way (cue competition $X$ conditioned inhibition) ANOVA was performed on this trial. It revealed only a main effect of cue competition $[F(1,27)=73.93]$, suggesting that the two groups that received the cue-competition treatment (Groups CC_CI and CC_NI) suppressed less to CS X than the two groups that did not (Groups NC_CI and NC_NI). These results provide evidence that $\mathrm{CS}$ A reduced conditioned performance to CS X in the two cue-competition groups.

Stage 3 (conditioned inhibition training). Two rats in Group CC_CI and 1 rat in Group NC_CI failed to master the discrimination between $\mathrm{B}+$ and $\mathrm{BA}-$ (averaged over the last half of training, the mean suppression ratio to $\mathrm{BA}-$ minus the mean suppression ratio to $\mathrm{B}+<+.05$ ). Consequently, these rats were removed from the study, and degrees of freedom in subsequent analyses are suitably reduced. Figure 3 (top panel) shows the results of the Pavlovian conditioned inhibition training that was given to Groups CC_CI and NC_CI. Early in this training, the BA compound tended to evoke more suppression

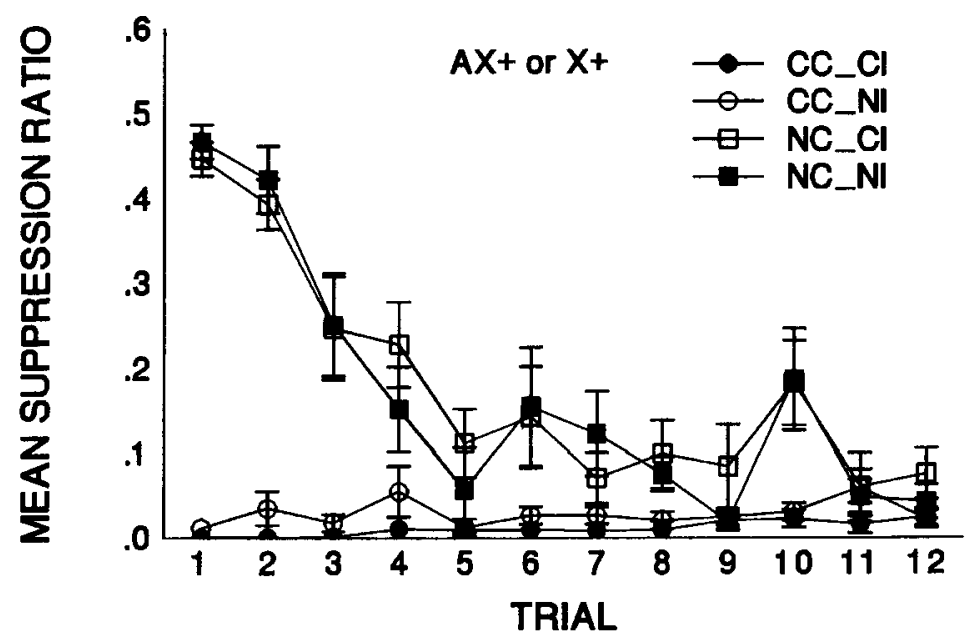

Figure 1. Acquisition of conditioned barpress suppression to the $\mathrm{AX}$ compound for Groups CC_CI and CC_NI and to CS X for Groups NC_CI and NC_NI during Stage 2 of Experiment 1. Error bars show \pm 1 SEM. 


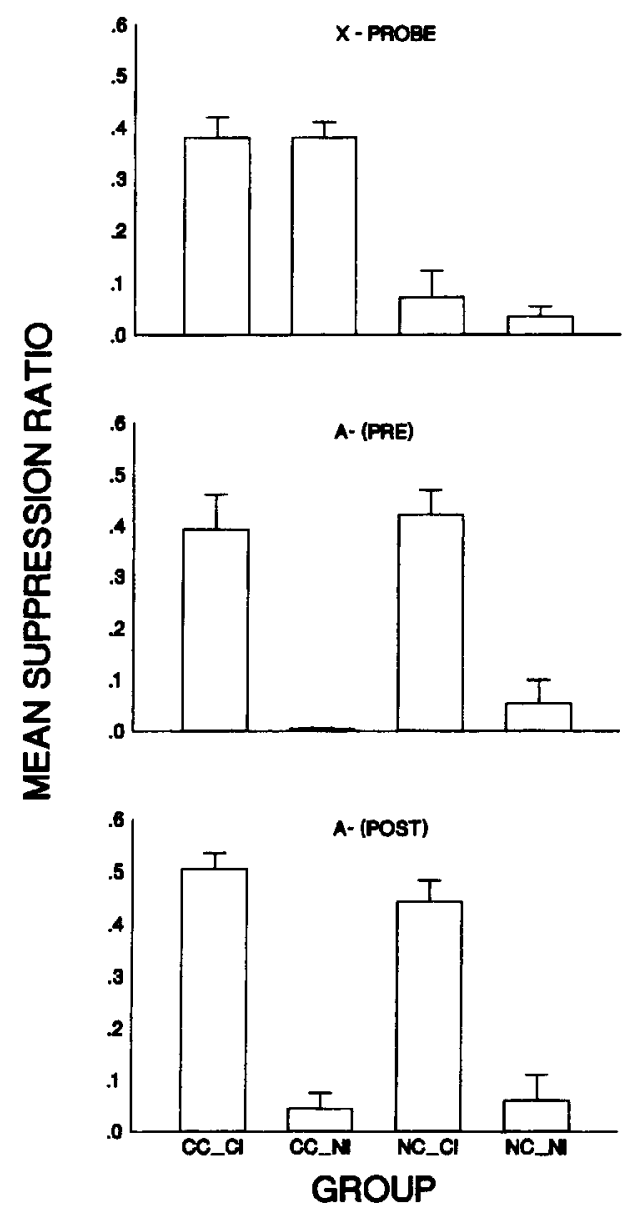

Figure 2. Top panel: Suppression on the $X-$ probe trial on Day 5 of Stage 2 in Experiment 1. Middle panel: Suppression to CS $A$ at the end of differential treatment in Stage 3 and just before (pre) the crucial test of CS X. Bottom panel: Suppression to CS A in Stage 5 just after (post) the test of CS X. Error bars show \pm 1 SEM.

than did the $B$ element. This is to be expected, because the excitation conditioned separately to B and to A should summate when the two CSs are compounded. Around Day 11 , however, suppression began to weaken to the BA compound. On Day 24, suppression to BA was significantly weaker than suppression to B [correlated $t(12)=$ 25.82]. This data pattern is consistent with (but does not demand) the interpretation that CS A became increasingly inhibitory with training and that its inhibition offset B's excitation.

Figure 3 (bottom panel) shows the results of the $\mathrm{B}+$, $\mathrm{C}-$ training given to Groups CC_NI and NC_NI. Both groups clearly discriminated between the two stimuli from the outset. That is, they suppressed throughout training to $\mathrm{B}+$ but not to $\mathrm{C}-$.

Figure 2 (middle panel) shows the results of the last A- probe trial the groups received in Stage 3. A cue competition $\times$ conditioned inhibition ANOVA was performed on this trial. Only the main effect of conditioned inhibition was significant $[F(1,24)=73.29]$. This result means that the two groups that received conditioned inhibition training (Groups CC_CI and NC_CI) suppressed less to CS A than the two groups that did not (Groups CC_NI and NC_NI). Thus, all the preconditions were now in place to permit us to ask whether weakening conditioned responding to CS A would reduce A's ability to compete with conditioned performance to $X$.

Stage 4 (extinction test to $X$ ). Figure 4 shows the results of Stage 4, the critical extinction test to CS X. A three-way (cue competition $X$ conditioned inhibition $X$ trial) ANOVA was performed on the data. It revealed significant effects of cue competition $[F(1,24)=50.25]$, trial $[F(5,120)=5.78]$, and the cue competition $\times$ trial interaction $[F(5,120)=3.15]$. No other effects were significant. The significant effect of cue competition suggests that the two groups subjected to a cue-competition procedure (Groups CC_CI and CC_NI) suppressed less to $\mathrm{CS} \mathrm{X}$ than the two groups that did not receive such training (Groups NC_CI and NC_NI). That is, CS A reduced conditioned performance to $\mathrm{CS} X$ in Groups CC_CI and CC_NI. There was no hint in the data that conditioned inhibition training (intended to weaken the putative $\mathrm{A}-\mathrm{US}$ and $\mathrm{X}-\mathrm{A}$ associations) enhanced performance to CS X (compare Groups CC_CI vs. CC_NI).

During the crucial extinction test of $\mathrm{CS} X$, the groups did not differ in their pre-CS response rates. The group mean rates here and in other important test stages are shown in Table 2. In each of these stages, ANOVAs such as those used to analyze the corresponding suppression ratios revealed no effects involving groups to be significant.

Stage 5 (extinction test to A). The results of the nonreinforced CS A trial that followed the extinction test of $\mathrm{X}$ are shown in Figure 2 (bottom panel). A cue competition $X$ conditioned inhibition ANOVA conducted on this trial revealed only an effect of conditioned inhibition $[F(1,24)=102.79]$. This result is further evidence that conditioned inhibition training weakened the ability of CS A to evoke suppression. Indeed, there is no hint of any spontaneous recovery in Group CC_CI.

\section{Discussion}

One of two groups that had received a cue-competition treatment $(\mathrm{A}+$ then $\mathrm{AX}+)$ was next given a conditioned inhibition treatment $(\mathrm{B}+, \mathrm{BA}-)$. Besides weakening the $\mathrm{X}-\mathrm{A}$ association, this treatment was designed to weaken the excitatory value of CS A and perhaps to transform A from a conditioned excitor to a conditioned inhibitor. Performance-deficit theories of cue competition predict that weakening CS A's excitation should allow an X-US association that was strong at the end of $\mathrm{AX}+$ training to generate performance when $\mathrm{X}$ is subsequently tested in isolation. Recent acquisition-focused models, such as the revised R-W rule (Van Hamme \& Wasserman, 1994) and the revised SOP theory (Dickinson \& Burke, 1996), predict that a weak $\mathrm{X}$-US association should gain strength with each $\mathrm{A}-$ (and especially $\mathrm{BA}-$ ) trial that follows $\mathrm{AX}+$ training. Our $\mathrm{B}+, \mathrm{BA}-$ treatment seemed to be suc- 

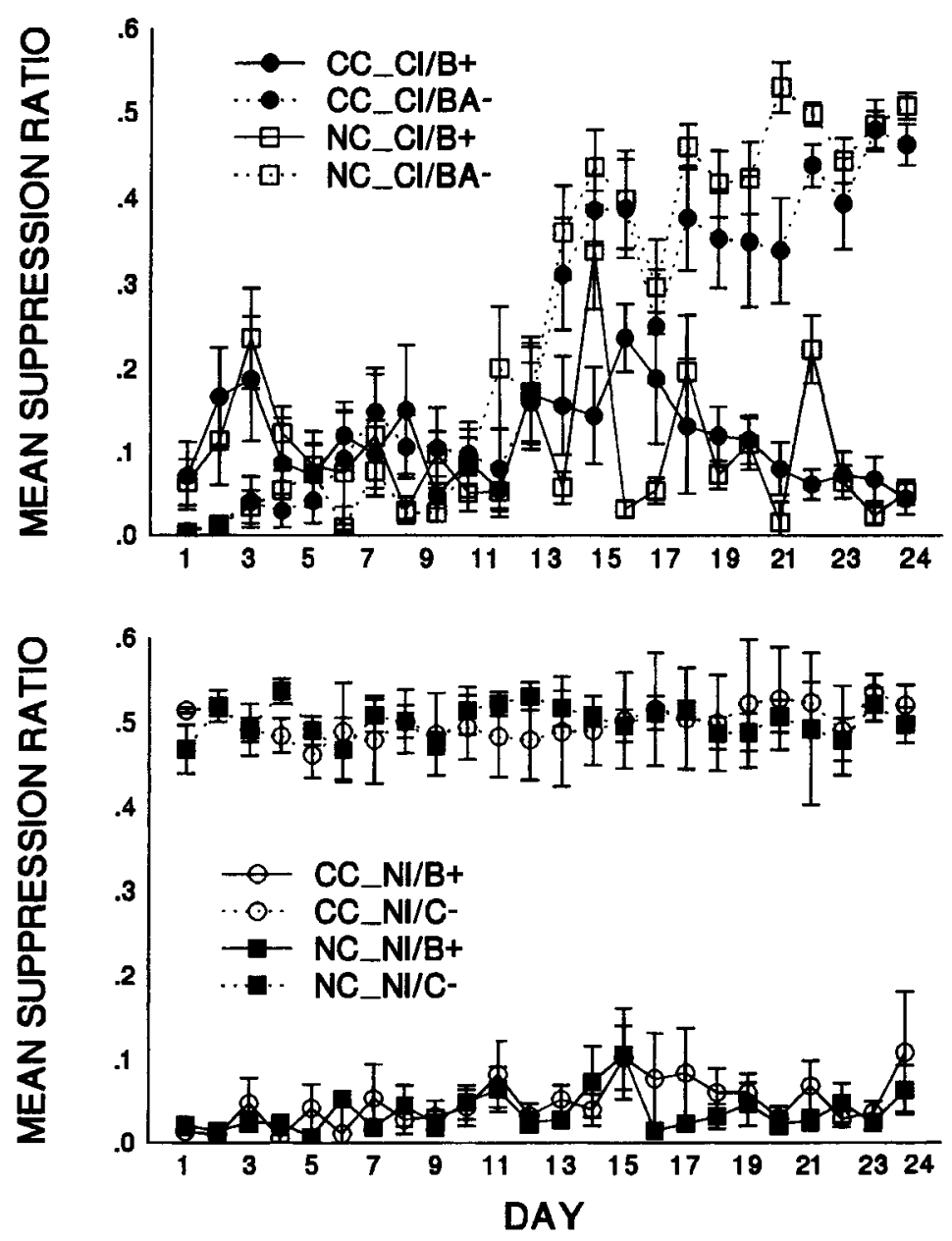

Figure 3. Top panel: Suppression on $\mathrm{B}+$ and $\mathrm{BA}-$ trials during conditioned inhibition training in Experiment 1 for Groups CC_CI and NC_CI in Stage 3. Bottom panel: Suppression on $\mathrm{B}+$ and $\mathrm{C}-$ trials for Groups $\mathrm{CC}$ _NI and NC_NI in Stage 3. Error bars show \pm 1 SEM.

cessful, in that, by the end of it, only CS B evoked conditioned suppression of barpressing. The BA compound did not; nor did CS A in isolation. Furthermore, no spontaneous recovery of conditioned suppression to CS A was observed in a final test conducted after extinction tests to CS X. Despite our apparent success at weakening the A-US association in this group (or at holding it in check with a competing A-no-US association), the group showed a strong cue-competition effect relative to control groups; indeed, it did not differ from another group that also received a cue-competition treatment but for which CS A was left highly excitatory.

Although our results are consistent with early learningdeficit interpretations of cue-competition effects (Kamin, 1968; Mackintosh, 1975; Pearce \& Hall, 1980; Rescorla \& Wagner, 1972; Wagner, 1981), those interpretations may be questioned if, in fact, the effects we have attributed to cue competition are instead due to generalization decrement. Thus, both of our cue-competition groups,
CC_Cl and CC_NI, received testing of X following training of AX. Their two comparison groups, $\mathrm{NC}$ CI and NC_NI, received testing of $X$ following training of $X$. Clearly, the training stimulus differed from the test stimulus for the two CC groups but not for the two NC groups. The two CC groups would therefore be expected to show generalization decrement during the test. Perhaps their weak suppression in the test sessions was due to this generalization decrement and not to cue competition. Experiment 2 tested this possibility.

\section{EXPERIMENT 2}

Pearce (1987) has suggested that adding a novel A to a conditioned $X$ would produce a level of generalization decrement similar to that produced by removing A from a conditioned $\mathrm{AX}$ compound. If Experiment 1 had included a group conditioned with $\mathrm{X}$ and tested with $\mathrm{AX}$, that group would have provided a measure of general- 


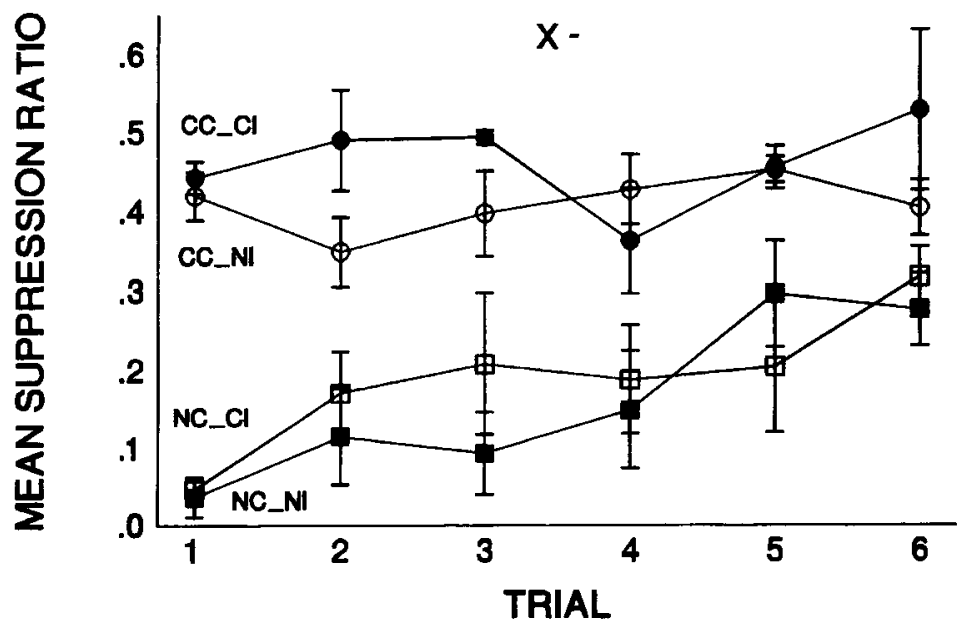

Figure 4. Suppression to CS $X$ during the extinction test for cue competition in Experiment 1. Error bars show $\pm 1 S E M$.

ization decrement. If that group then showed stronger suppression in its $\mathrm{AX}$ test than the two $\mathrm{CC}$ groups showed in their $\mathrm{X}$ test, then the evidence for cue competition in the two $\mathrm{CC}$ groups would have been much stronger than it was (for similar logic, see Blaisdell, Denniston, \& Miller, 1998). In Experiment 2, we sought to provide such a control for generalization decrement while replicating the main findings of Experiment 1 . At the end of the experiment, we added a transfer summation test and a retardation test (Rescorla, 1969) in search of more evidence that the conditioned inhibition treatment may have transformed CS A from a conditioned excitor to a conditioned inhibitor.

\section{Method}

Subjects and Apparatus. The subjects were 32 experimentally naive male albino rats of Charles River stock, bred in our colony at the University of Massachusetts, Amherst. At the start of deprivation, they ranged in age from 71 to 94 days and in weight from 353 to $580 \mathrm{~g}$. Housing and animal care procedures were unchanged, as was the apparatus.

Procedure. Preliminary barpress training was identical to that of Experiment 1. Then, as shown in Table 3, three groups of rats $(n \mathrm{~s}=$ 8 ) received the treatments given to Groups CC_CI, CC_NI, and NC_NI in Experiment 1; accordingly, their group names were unchanged. The fourth group, Group GenDec $(n=8)$, received a treatment similar to that of Group NC_NI but modified in Stages 1 and 4 to permit us to assess the degree of generalization decrement caused by combining a neutral CS A with a well-conditioned CS X. If generalization decrement occurs, we should expect less suppression to the AX compound in Group GenDec than to the $\mathrm{X}$ element in Group NC_NI. The question would then become: Is the suppression to AX in Group GenDec just as weak as the suppression to the $\mathrm{X}$ element in the two cue-competition groups (Groups $\mathrm{CC}$ CC_NI)? If it is not, then the weaker suppression in the two CC groups would be attributed to some process in addition to the generalization decrement caused in those groups when CS A was removed from the conditioned AX compound in order to test $X$ alone. Presumably, that additional process would be cue competition.
Stage $1(A+$ and $B+$ training). For the first three groups in Table 3 , this stage replicated exactly the $A+$ and $B+$ training of Experiment 1. For Group GenDec, however, CS C replaced CS A. The aim was to match this group to the others in terms of the number and spacing of reinforced trials while simultaneously maintaining the neutrality of CS A.

Stage $2(A X+$ or $X+$ training). This stage also replicated that of Experiment 1 for the first three groups in Table 3. Group GenDec, like Group NC_NI, received training to the $\mathrm{X}$ element in isolation so as to avoid cue competition in either of these groups. As before, this stage included a probe test of CS X for the first three groups of Table 3 . This test was designed to provide evidence of cue competition prior to the conditioned inhibition training of CS A in the next phase. During the probe test, Group GenDec was presented with the $\mathrm{AX}$ compound so as to provide a preliminary assessment of the generalization decrement caused by adding a nonconditioned CS A to the excitatory CS X.

Stage 3 (conditioned inhibition training). As in Experiment 1, this phase was designed to use conditioned inhibition training $(B+$, $\mathrm{BA}-$ ) in Group CC_CI to weaken the putative $\mathrm{X}-\mathrm{A}$ association together with the excitation conditioned to the competing cue, CS A. On each day, Group CC_CI received either two B+ and two BAtrials (Days 6, 10,15,18,19,21,23, 25, 26, and 27) or one B+ and three $\mathrm{BA}$ - trials (remaining days). In addition, this group received one $A$ - trial per day. We introduced the $A$ - trial on Day 1 here instead of on Day 11, as in Experiment 1, hoping that the earlier introduction of $\mathrm{A}-$ trials would facilitate the discrimination between $B$ and BA. In addition, we conducted conditioned inhibition training for 28 days here instead of the original 24. Altogether, the group that received conditioned inhibition training experienced 102 nonreinforced exposures (each $2 \mathrm{~min}$ ) to $\mathrm{CS} \mathrm{A}$, either alone or in com-

Table 2

Pre-CS Rates (per $2 \mathrm{~min}$ ) in Various Stages of Experiment 1

\begin{tabular}{ccccc}
\hline Group & X-Probe & Stage 3 A- & Test X- & Stage 5 A- \\
\hline CC_CI & 45 & 58 & 53 & 68 \\
CC_NI & 65 & 66 & 55 & 85 \\
NC_CI & 40 & 79 & 64 & 88 \\
NC_NI & 68 & 76 & 62 & 94 \\
\hline
\end{tabular}

Note-The "-" sign indicates that the CS was not followed by the US. 
Table 3

Design of Experiment 2

\begin{tabular}{cccccccc}
\hline Group & Stage 1 & Stage 2 & Stage 3 & Test & Test & Sum & Ret \\
\hline CC_CI & $\mathrm{A}+, \mathrm{B}+$ & $\mathrm{AX}+$ & $\mathrm{B}+, \mathrm{BA}-$ & $\mathrm{X}-$ & $\mathrm{A}-$ & $\mathrm{C}+, \mathrm{CA}-$ & $\mathrm{A} \pm$ \\
CC_NI & $\mathrm{A}+, \mathrm{B}+$ & $\mathrm{AX}+$ & $\mathrm{B}+, \mathrm{C}-$ & $\mathrm{X}-$ & $\mathrm{A}-$ & $\mathrm{C}+, \mathrm{CA}-$ & $\mathrm{A} \pm$ \\
NC_NI & $\mathrm{A}+, \mathrm{B}+$ & $\mathrm{X}+$ & $\mathrm{B}+, \mathrm{C}-$ & $\mathrm{X}-$ & $\mathrm{A}-$ & $\mathrm{C}+, \mathrm{CA}-$ & $\mathrm{A} \pm$ \\
GenDec & $\mathrm{C}+, \mathrm{B}+$ & $\mathrm{X}+$ & $\mathrm{B}+, \mathrm{C}-$ & $\mathrm{AX}-$ & $\mathrm{A}-$ & $\mathrm{C}+, \mathrm{CA}-$ & $\mathrm{A} \pm$
\end{tabular}

Note-CS A = noise off; CS B = tone; $\mathrm{CS} \mathrm{C}=$ click; CS X = light. Sum $=$ summation test; Ret $=$ retardation test. The "+" sign indicates that a CS was paired with a shock (US). The "-" sign indicates that a CS was not paired with a US.

pound with B, for a total of 204 min of nonreinforced exposure. As in Experiment 1, the remaining groups in this phase received training of the form $\mathrm{B}+, \mathrm{C}-$. Besides matching these three groups with Group $\mathrm{CC} C \mathrm{CI}$ in terms of the number and spacing of reinforced and nonreinforced trials, this training was designed to leave the value of CS A unchanged. However, for these groups, there were probe assessments of that value. A single $\mathrm{A}-$ probe trial replaced a $\mathrm{C}$ - trial on Days 1 and 28 and (by mistake) on Day 4.

Stage 4 (extinction test to $X$ ). For the first three groups in Table 3 , the test of CS X that followed conditioned inhibition training was identical to the test of $X$ in Experiment 1. For Group GenDec, however, the AX compound was tested instead of the X element. On the basis of the results of Experiment 1, we expected Groups $\mathrm{CC}$ Cl and $\mathrm{CC}_{-} \mathrm{NI}$ to show much weaker suppression than Group NC_NI. At issue is whether Groups CC_CI and CC_NI will also show weaker suppression to $\mathrm{X}$ than Group GenDec shows to $\mathrm{AX}$.

Stage 5 (extinction test to A). A one-trial extinction test of A's effects was conducted as in Experiment 1 for all four groups.

Stage 6 (conditioning a transfer excitor). This stage lasted for 4 days, each with two $\mathrm{C}+$ trials. The aim was to establish CS $\mathrm{C}$ as an excitor in all groups in preparation for a transfer summation test in Stage 7.

Stage 7 (summation test). This stage was a summation savings test for conditioned inhibition (Rescorla, 1971). It lasted for 6 days, each with two $\mathrm{C}+$ trials and two $\mathrm{CA}-$ trials. We assumed that if CS A had acquired any inhibitory value in Group CC_CI, it should come to inhibit responding to $\mathrm{CS} C$ more rapidly in that group than in Group GenDec, for which CS A should have been relatively neutral.

Stage 8 (retardation test). In this final stage, CS A was presented twice daily for 5 days. Half of these presentations were paired with shock. The order of $\mathrm{A}+$ and $\mathrm{A}-$ trials across the 5 days was -+ , ,,+--+++ , and -- . If CS A had acquired any inhibitory value in Group CC_CI during conditioned inhibition training, then we might expect conditioned suppression to CS A to be acquired more slowly in Group CC_CI than in Group GenDec, for which CS A should have been more neutral (Rescorla, 1969).

\section{Results}

Experiment 2 successfully replicated the main finding of Experiment 1. That is, subjecting CS A to Pavlovian conditioned inhibition training after $\mathrm{AX}+$ training and before testing CS $X$ failed to reduce cue competition in Group CC_CI relative to Group CC_NI. Moreover, the weak suppression in both of these groups could not be explained in terms of generalization decrement because it was weaker than the suppression in Group GenDec when the nonconditioned CS A was added to the conditioned CS X.

Stage $1(A+$ and $B+)$. Acquisition of suppression to CSs A and B proceeded normally in the first three groups of Table 3, as did suppression to CSs B and C in Group
GenDec. No rats failed to condition. For CS A, the mean suppression ratio dropped from .50 on Trial 1 to .08 on Trial 6. For CS B, the drop was from .46 to .05 . For CS C, the drop was from .48 to .05 . The rates of acquisition appeared to be similar for all three CSs, and, as in Experiment 1 , the groups did not differ in their overall levels of suppression or in their rates of acquisition to either CS A or CS B.

Stage $2(\mathbf{A X}+\mathbf{v s .} \mathbf{X}+)$. The results of this stage are not shown but looked much like those plotted in Figure 1. That is, the groups that had previously been conditioned to CS A (Groups CC_CI and CC_NI) suppressed at the outset to the $\mathrm{AX}$ compound (mean suppression ratio $=$ .07 on Trial 1) and continued to do so throughout (mean suppression ratio $=.06$ on Trial 12). In contrast, the two groups conditioned to $\mathrm{X}$ in isolation for the first time (Groups NC_NI and GenDec) suppressed weakly to X at the outset (mean suppression ratio for both groups combined $=.42$ on Trial 1) and gradually acquired suppres-

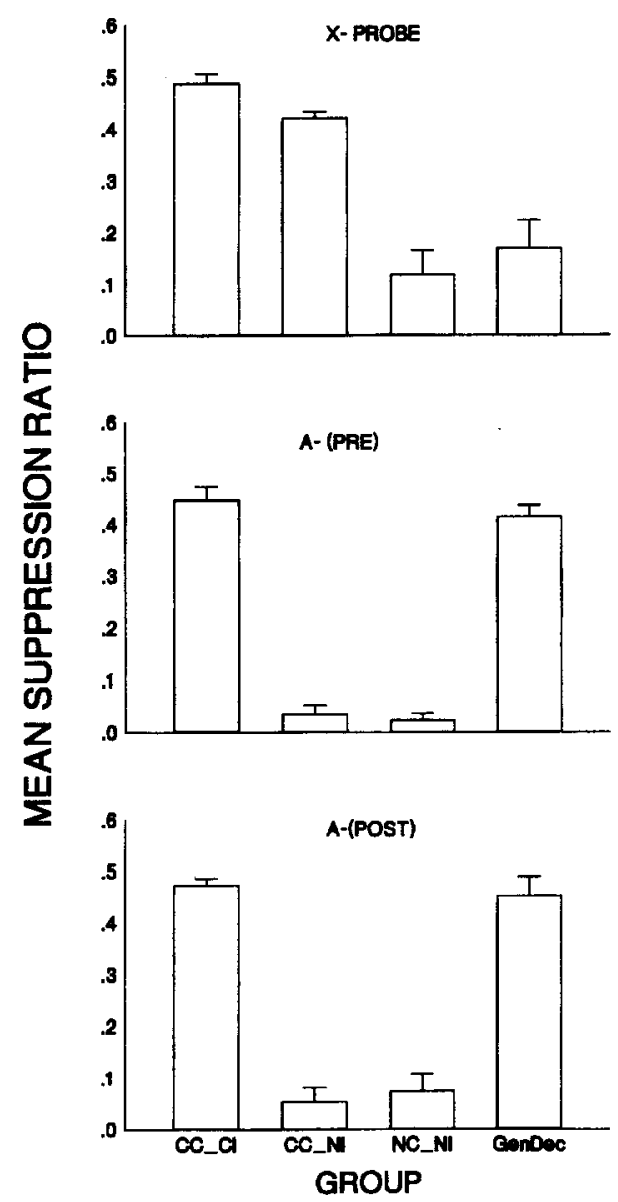

Figure 5. Top panel: Suppression on the $X$ - probe trial on Day 5 of Stage 2 in Experiment 2. Middle panel: Suppression to CS $A$ at the end of differential treatment in Stage 3 and immediately before (pre) the crucial test of CS X. Bottom panel: Suppression to CS A in Stage 5 immediately following (post) the test of CS X. Error bars show $\pm 1 S E M$. 
sion to that CS (mean suppression ratio for both groups combined $=.03$ on Trial 12). The two groups' rates of acquisition appeared to be similar.

Of more interest in this stage were the results of the probe trial given on Day 5. This trial provided a preliminary measure of cue competition in Groups $\mathrm{CC}_{-} \mathrm{CI}$ and CC_NI and of the generalization decrement produced in Group GenDec when, for the first time, the neutral CS A was compounded with the conditioned CS X. These results, shown in the top panel of Figure 5, reveal weak suppression in the two cue-competition groups (Groups CC_CI and $\mathrm{CC}_{-} \mathrm{NI}$ ) and strong suppression in the two control groups (Groups NC_NI and GenDec). One-way ANOVA revealed a significant effect of group $[F(3,28)=$ 20.76]. Planned $t$ tests using the error term and degrees of freedom from the ANOVA showed that Groups CC_CI and CC_NI did not differ $[t(28)=1.19]$ but that, together, they did differ from Group GenDec $[t(28)=5.04]$. Group GenDec, in turn, did not differ from Group NC_NI $(t<1)$. Thus, Group GenDec showed little evidence for generalization decrement. These results imply that the weak suppression in the two cue-competition groups was indeed due to cue competition and not to generalization decrement.

Stage 3 (conditioned inhibition training). Three of the 8 rats in Group CC_CI failed to learn the discrimination between $\mathrm{B}+$ and $\mathrm{BA}-$ (averaged over the last half of training, the mean suppression ratio to $\mathrm{BA}-$ minus mean suppression ratio to $\mathrm{B}+<+.05$ ). These 3 rats were dropped from the study at this point, and degrees of freedom in all subsequent statistical analyses were reduced accordingly. The top panel of Figure 6 shows the results of the conditioned inhibition training for the remaining 5 rats in the group. It is clear that these rats gradually formed a strong discrimination between $\mathrm{B}+$ and $\mathrm{BA}-$ over the course of this training. On the last day, suppression to BA was significantly weaker than suppression to $\mathrm{B}$ [correlated $t(4)=6.72$ ].

The bottom panel of Figure 6 shows the results for Group GenDec during the B+, C-trials of Stage 3. CSs
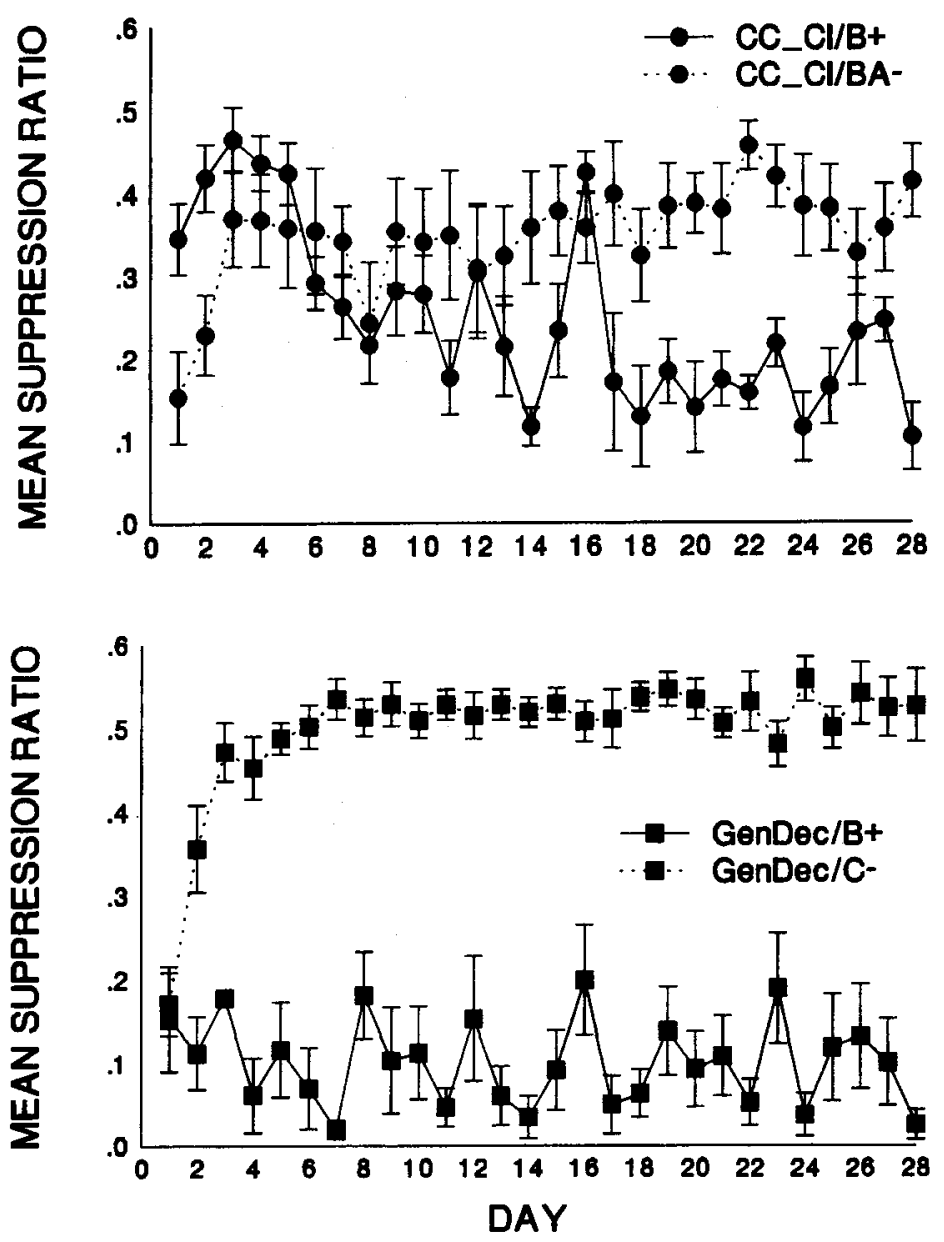

Figure 6. Top panel: Suppression on $B+$ and $B A-$ trials during conditioned inhibition training in Experiment 2 for Group CC_CI in Stage 3. Bottom panel: Suppression on B+ and C - trials for Group GenDec in Stage 3. Error bars show $\pm 1 S E M$. 
B and C had each been conditioned in Stage 1, so each evoked strong suppression at the start of Stage 3. Only CS B, however, maintained that ability.

The results for Groups CC_NI and NC_NI during their $\mathrm{B}+, \mathrm{C}-$ trials are not shown. Those results looked much like those in the bottom panel of Figure 3, obtained for comparable groups in Experiment 1 . Thus, for both groups, CS B, which had been reinforced in Stage 1 and continued to be reinforced in Stage 3, always evoked strong suppression. In contrast, CS C, which had never been paired with shock and continued to be unpaired in Stage 3, never evoked suppression.

The middle panel of Figure 5 shows the results of the final A- probe trial, which was given on the last day of Stage 3. An ANOVA performed on these data revealed a significant effect of group $[F(3,25)=121.9]$. The suppression in Group CC_CI, which had received $\mathrm{B}+, \mathrm{BA}-$ training designed to reduce the excitatory value of CS A, showed no stronger suppression to $A$ than did Group GenDec, for which A had never been paired with shock. Moreover, both of these groups suppressed much less than Groups CC_NI and NC_NI, for which no attempt was made to reduce the excitation previously conditioned to CS A.

Stage 4 (extinction test of CS X). Figure 7 shows the results of the crucial test of CS X in Stage 4 for the first three groups in Table 3. For Group GenDec, the AX compound was tested instead of CS X. A group $\times$ trial ANOVA performed on these data found significant effects of group $[F(3,25)=4.91]$ and trial $[F(5,125)=4.03]$. A second ANOVA isolating Groups $\mathrm{CC} \_\mathrm{CI}$ and $\mathrm{CC} \_\mathrm{NI}$ found that they did not differ $[F(1,11)=1.21]$. A third ANOVA found that these two groups combined suppressed significantly less than Group GenDec $[F(1,19)=$ 9.55]. A fourth ANOVA isolating Groups GenDec and NC_NI found no significant effect of group $(F<1)$; how-
Table 4

Pre-CS Rates (per 2 min) in Various Stages of Experiment 2

\begin{tabular}{lcccccc}
\hline Group & X- Probe & Stage 3 A & Test X- & Test A- & Sum & Ret \\
\hline CC_CI & 42 & 41 & 39 & 51 & 37 & 50 \\
CC_NI & 40 & 46 & 40 & 53 & 39 & 48 \\
NC_NI & 49 & 66 & 53 & 57 & 43 & 59 \\
GenDec & 37 & 65 & 53 & 60 & 39 & 51 \\
\hline
\end{tabular}

Note-The "- " sign indicates that the CS was not followed by the US. Sum $=$ summation test; Ret $=$ retardation test.

ever, the group $\times$ trial interaction approached significance $[F(5,70)=2.12, p=.07]$. This interaction reflects the tendency for Group GenDec to suppress less than Group NC_NI on the first three test trials. In sum, the results imply that some generalization decrement may have occurred in Group GenDec but not enough to explain the significantly weaker suppression in the two cuecompetition groups (Groups CC_CI and CC_NI). This weaker suppression, then, is presumably due to cue competition. Furthermore, devaluing the competing cue (CS A) by subjecting it to conditioned inhibition training following AX training did not weaken CS A's ability to compete effectively with CS X. These latter results and conclusions are entirely consistent with those of Experiment 1.

During the crucial extinction test of CS X, the groups did not differ in their pre-CS response rates. The group mean rates here and in other important test stages are shown in Table 4. In each of these stages, ANOVAs similar to those performed on the corresponding suppression ratios revealed no effects involving groups to be significant.

Stage 5 (extinction test of CS A). The bottom panel of Figure 5 shows the results of testing CS A on the day following the test of CS X. Consistent with the results of Experiment 1, Group CC_CI showed no evidence of spontaneous recovery of suppression to CS A, suppressing no more than Group GenDec, which had never received

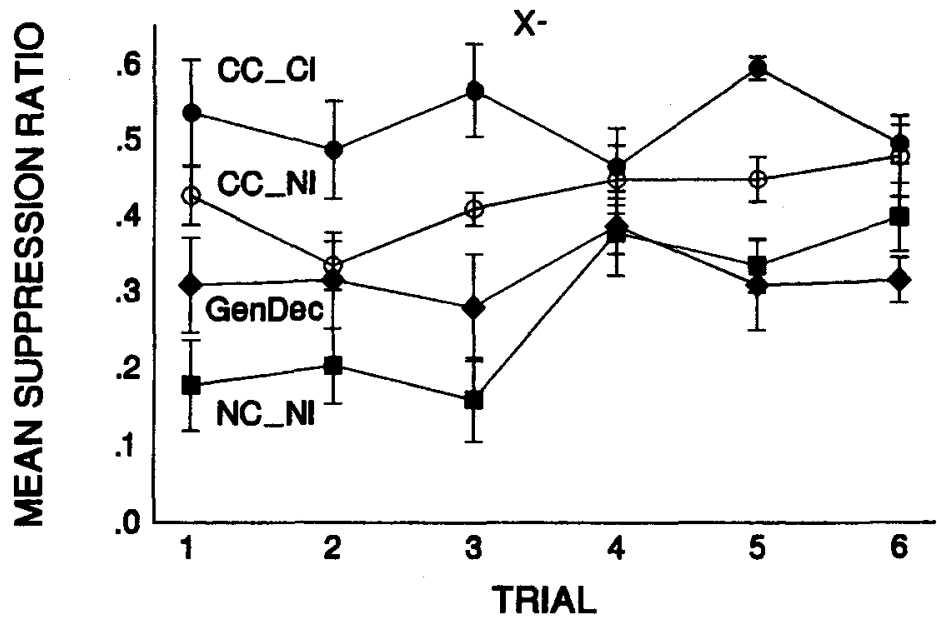

Figure 7. Suppression to $\mathrm{CS} X$ during the extinction test for cue competition in Experiment 2. Error bars show $\pm 1 S E M$. 

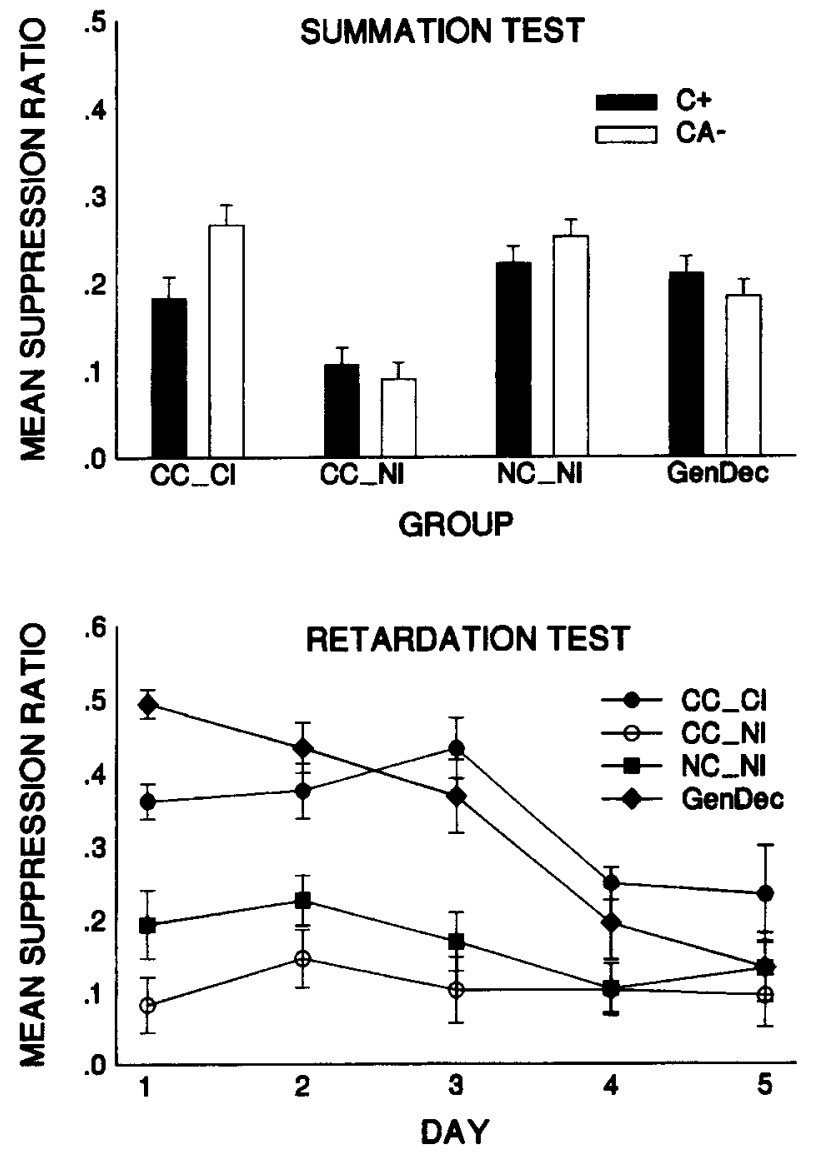

Figure 8. Top panel: Suppression to $\mathrm{C}+$ and $\mathrm{CA}-$ trials during the summation test in Experiment 2 for Groups $\mathrm{CC}_{-} \mathrm{CI}, \mathrm{CC} \mathrm{C}_{-} \mathrm{NI}$, NC_NI, and GenDec. Given that within-group differences in response to different trial types were of interest, the error bars show \pm 1 standard error of the difference, as derived from the withingroup error term in the group $\times$ trial type ANOVA. Bottom panel: Suppression to $\mathrm{CS} A$ during the retardation test for Groups CC_CI, CC_NI, NC_NI, and GenDec. Error Bars show \pm 1 SEM.

CS A paired with shock. In contrast, CS A evoked strong suppression in Groups CC_NI and NC_NI. An ANOVA performed on these data found a significant effect of group $[F(3,25)=42.71]$.

Stage 6 (conditioning a transfer excitor). In this stage, CS C was paired with shock for all groups. Because the groups had different histories with CS C, they acquired suppression at different rates (data not shown). The rate was fastest in Group CC_CI, next fastest in Group GenDec, and slowest in Groups CC_NI and NC_NI.

Stage 7 (transfer summation test). This stage consisted of training of the form $\mathrm{C}+, \mathrm{CA}-$. To the extent that CS A had been transformed into a conditioned inhibitor for Group CC_CI, CS A was expected to acquire the potential to weaken suppression to CS C in that group faster than in the other groups. On Day 1 of this training, the addition of CS A to the already-conditioned CS C had no effect in Group CC_CI but increased suppression in all the other groups. On Day 2, CS A tended to weaken sup- pression to CS C in Group CC_CI, and this tendency persisted across the remaining days. In contrast, CS A had the opposite effect in all of the other groups on at least Day 2. On Day 3, we failed to record the results for Group GenDec, due to experimenter error; therefore, the top panel of Figure 8 shows the results of summation testing averaged over Days 4,5 , and 6 only. A group $\times$ trial type ANOVA performed on these data showed a significant group $\times$ trial type interaction $[F(3,25)=5.40]$. Followup $t$-test comparisons using the within-groups error term from the ANOVA found that CS A significantly weakened suppression to CS C only in Group CC_CI $[t(25)=$ 3.46]. Importantly, that group was the only group for which CS A had been subjected to Pavlovian conditioned inhibition training in Stage 3. In Groups CC_NI and NC_NI, CS A had been established as an excitor; in Group GenDec, CS A had neither been paired with shock nor been subjected to a $\mathrm{B}+, \mathrm{BA}-$ procedure. The results suggest, therefore, that, for Group CC_CI in the transfer summation test, there was some savings of inhibition conditioned to CS A during B+, BA- training of Stage 3.

Stage 8 (retardation test). The results of the retardation test with CS A are plotted, blocked over days, at the bottom of Figure 8. Throughout this training, CS A evoked strong suppression in Groups CC_NI and NC_NI. These groups had been conditioned to CS A in Stage 1 , and no attempt had been made to weaken that conditioning except for the few probe tests of $\mathrm{A}$ alone and for the brief exposure to the $\mathrm{C}+, \mathrm{CA}-$ procedure of Stage 7 . In contrast, CS A evoked weak suppression at the outset of Stage 8 for Groups CC_CI and GenDec. Thus, the differences that existed among groups in Stage 5's test of A (see bottom panel of Figure 5) were maintained at the start of Stage 8. With continued training, however, Groups CC_CI and GenDec gradually acquired suppression to CS A. A question of interest is whether that acquisition was slower in Group CC_CI than in Group GenDec. Group CC_CI had received extensive $\mathrm{B}+, \mathrm{BA}-$ training in Stage 3 following A-US pairings in Stage 1. Group GenDec had never received CS A paired with shock and had received no $\mathrm{B}+, \mathrm{BA}-$ training. A group $\times$ day ANOVA isolating these two groups found significant effects of day and the group $\times$ day interaction $\left[F_{\mathbf{S}}(4,44)>\right.$ 4.51]. Follow-up $t$ tests, however, failed to reveal any significant differences between the two groups on any given day $[t s(11)<1.95]$. Thus, the significant interaction can only be interpreted to mean that the acquisition function for Group CC_CI was flatter than the function for Group GenDec. The flatness of the function for Group CC_CI might be construed as evidence of retarded acquisition in that group. This interpretation may be questioned, however, to the extent that the two functions did not begin at the same level. What is less ambiguous is that Group CC_CI showed no sudden increase in suppression to CS A when $A$ was paired with shock. Such an increase would be expected from the view that a latent A-US association had remained intact for this group after Stage 3 despite our attempts to weaken it or reverse it. If there had been 
a latent $\mathrm{A}-\mathrm{US}$ association, our $\mathrm{A}-\mathrm{US}$ pairings should have excelled as retrieval cues, bringing the A-US association quickly to the fore.

\section{GENERAL DISCUSSION}

We used conditioned inhibition training in an effort to weaken the putative within-compound $(\mathrm{X}-\mathrm{A})$ association together with the putative A-US association following a two-stage cue-competition procedure $(\mathrm{A}+$ then $\mathrm{AX}+)$. We found that the conditioned inhibition procedure did not weaken CS A's ability to serve as a competing cue. It did not restore responding to CS X. The major advance of this work over the recent report by Rauhut et al. (1999) is that here we found no evidence of spontaneous recovery of responding to CS A after testing for responding to CS X. That is, CS A appeared incapable of evoking conditioned fear immediately before and immediately after $\mathrm{X}$ was tested. Thus, there was no evidence here for a latent A-US association that might have generated spontaneous recovery. And, as just noted above, even when we then paired CS A with the US, we found no sudden increase in responding to CS A (rapid reacquisition). Indeed, reacquisition was no faster and may actually have been slower than acquisition in a control group for which A had never before been paired with the US. We would have expected rapid reacquisition if there had been a latent A-US association that needed only to be retrieved by some retrieval cue in order to be expressed. What could be a better retrieval cue than an A-US pairing for retrieving a latent A-US association?

These results speak strongly against current performance-deficit theories of cue competition. These theories hold that when $\mathrm{X}$ is tested, it evokes a representation of CS A, its companion during $\mathrm{AX}+$ training; CS A then evokes a representation of its US associate. Comparator theory asserts that responding to $\mathrm{X}$ is directly related to the strength of the $\mathrm{X}-\mathrm{US}$ association and inversely related to the product of the $\mathrm{X}-\mathrm{A}$ and $\mathrm{A}-\mathrm{US}$ associations. Retrieval-interference theory asserts that a strong A-US association can interfere with retrieval of an X-US association and thereby prevent performance to $X$.

Our evidence, however, suggested that, in one of our cue-competition groups, there was no strong A-US association either just before or just after testing for responding to $X$. Furthermore, exposing A repeatedly in the absence of $X$ (including presenting it in compound with $B$ ) should weaken not only the A-US association but also the $\mathrm{X}-\mathrm{A}$ association (Rescorla \& Freberg, 1978). This would further weaken the product of the X-A and A-US associations. For these reasons, it seems extremely implausible that, at the time of testing X, a strong A-US association could have prevented expression of the X-US association either by acting as a comparator or by interfering with retrieval of the X-US association.

In contrast, in another cue-competition group, the results implied that there was a very strong A-US association both before and after testing $\mathrm{X}$. For this group, that strong association should have thwarted expression of the $\mathrm{X}$-US association. Despite the differences in the presumed strengths of the A-US association in these two groups at the time that $\mathrm{X}$ was tested, the two groups were indistinguishable in their weak responding to X. Because the value of CS $A$ at the time of testing $X$ seemed to be irrelevant, we are left to conclude that the crucial factor in producing cue competition was the value of CS A at the time of $\mathrm{AX}+$ training. It seems likely that, during $\mathrm{AX}+$ training, the $\mathrm{X}$-US association was poorly formed in our cue-competition groups because of competition from the already-trained CS A. Thus, our results appear much more congenial with early learning-deficit theories of cue competition (Kamin, 1968; Mackintosh, 1975; Pearce \& Hall, 1980; Rescorla \& Wagner, 1972; Wagner, 1981) than with performance-deficit theories.

Our results are also not as predicted by recent acquisition-focused models, such as the revised R-W rule (Van Hamme \& Wasserman, 1994) and the revised SOP theory (Dickinson \& Burke, 1996). Those models agree with the early learning-deficit theories that a deficit in learning to $\mathrm{X}$ occurred during our $\mathrm{AX}+$ training. However, they predict increments in X's value when $A$ is subsequently nonreinforced. As explained in the introduction, they expect those increments to be especially large when $A$ is nonreinforced in the presence of an excitor, such as CS B. Therefore, our conditioned inhibition procedure $(\mathrm{B}+, \mathrm{BA}-)$ should have been especially effective in fostering increments to $X$. This incremental process, however, depends on CS A's ability to evoke a representation of its within-compound associate, X. Our conditioned inhibition procedure was designed expressly to weaken that within-compound association in order to provide a strong test of performance-deficit theories. By weakening that association, we necessarily constrained the incremental process. Still, these acquisition-focused models predict negatively accelerated learning curves, and we would therefore expect that the most important increments to $X$ would occur before the within-compound association had been substantially weakened.

Our conclusion does not rest on the demonstration that conditioned inhibition training actually transformed CS A into a conditioned inhibitor of fear. We assert only that the conditioned inhibition procedure weakened the excitatory value of CS A or held it in check with a competing CS-no-US association, not that it created a purely inhibitory CS A. Although our transfer summation test and our retardation test provided some evidence that CS A may have acquired some inhibitory value, that evidence was not overwhelming. To the extent that it exists at all, however, it only buttresses our argument. It does not in any way weaken it.

When extinguishing A or subjecting it to a conditioned inhibition procedure fails to enhance responding to CS X, advocates of performance-deficit theory can always suggest that not enough such training was given. Indeed, Blaisdell et al. (1999) have presented strong evidence that nonreinforced $A$ exposures must be conducted 
well beyond the point that $\mathrm{A}$ stops evoking a CR. Furthermore, they have suggested that a 50-to- 1 ratio of nonreinforced $\mathrm{A}$ exposures to $\mathrm{A}+$ or $\mathrm{AX}+$ trials might be required to eliminate cue-competition effects. One problem with this suggestion, however, is that Kaufman and Bolles (1981) were able to reverse the effects of overshadowing using only a 2-to-1 ratio of $\mathrm{A}-$ to $\mathrm{AX}+$ trials ( $5 \mathrm{AX}+$ trials followed by $10 \mathrm{~A}$ - trials). In addition, it is well known that the crucial parameter in extinction is not the number of nonreinforced CS exposures but rather the total duration of that exposure (Shipley, 1974). In this regard, each of the present experiments gave more extensive nonreinforced exposure of CS A than the most extensive exposure used by Blaisdell et al. (1999). In the present work, the competing cue, CS A, produced profound suppression in one group and no suppression in the other. The two groups differed behaviorally about as much as possible on this measure; yet, they suppressed similarly to the target CS, X. It is hard to see why any further differential treatment of CS A in the two groups should alter its ability to prevent conditioned performance to $\mathrm{X}$ in those groups. To argue otherwise is to give the appearance of saying that differential treatment is extensive enough only when responding to $X$ is enhanced in one of the groups, as performance-deficit theory predicts. That argument would render the performance-deficit hypothesis untestable.

Advocates of the recent acquisition-focused models described by Van Hamme and Wasserman (1994) and Dickinson and Burke (1996) would be unlikely to argue that we failed to give enough nonreinforced A trials. Because those models predict negatively accelerated learning curves, they would anticipate the largest increments to X's conditioned value to occur on the early BA- or A- trials. These theories would probably not place a premium on massive nonreinforced exposure of CS A.

In a personal communication, Ralph Miller (January 1999) noted that, in the work of Rauhut et al. (1999), CS A was always the termination of white noise. He suggested that animals might process the cessation of a stimulus for only a brief period and that this brief processing could reduce the impact of extensive extinction exposure to that cessation. Like Rauhut et al., we too used cessation of white noise as CS A. It would seem difficult to argue here, however, that CS A was processed only briefly during the conditioned inhibition procedure because CS A became so adept at reducing responding to CS B. The fact that it did so seems to imply that it was processed throughout much of its duration. One way to assess this processing idea directly is to ask whether, during the conditioning of such a $\mathrm{CS}$, responding differs during its first and second halves. Weaker responding in the second half of the CS would be consistent with Miller's suggestion. Accordingly, we examined the suppression in the first and second halves of CS A on the last trial of A+ training in Stage 1. For the 24 rats conditioned to CS A, the mean suppression ratios in its first and second halves were .06 and .08 , respectively. These values did not differ significantly [correlated $t(23)=1.27$ ]. Similarly, if rats stop processing $\mathrm{CS} \mathrm{A}$ (but not $\mathrm{B}$ ) during $\mathrm{B}+, \mathrm{BA}-$ training, then the effects of the fear excitor $(B)$ should remain constant for the duration of the BA compound, while the effects of the fear inhibitor (A) should weaken. This would mean that suppression to the BA compound should increase throughout its extent. To check on this possibility, we examined suppression in the first and second halves of the last BA - trial during conditioned inhibition training; we found the mean suppression ratios to be .40 and .46 in those two halves, the difference being small and in the wrong direction. In short, we find no evidence for a reduction of processing during the two halves of our 2min white-noise-cessation CS.

Until very recently, comparator theory's view of cue competition has been easy to distinguish from the learningdeficit theory's view. In contrast to learning-deficit theory, comparator theory has held that cue competition is something that takes place not at the time of training but rather at the time of testing. The theory has been a molar theory in that it has not been concerned about the molecular details of sequences of trial types during learning. For example, it distinguished itself from learning-deficit theories, such as Rescorla and Wagner's (1972) model, by predicting that it mattered little whether $\mathrm{A}-$ trials were given after $\mathrm{A}+$ training and before $\mathrm{AX}+$ training or were instead given after both $\mathrm{A}+$ and $\mathrm{AX}+$ training had been completed. Either procedure should weaken X's comparator A-US association at the time of testing and result in strong responding to $X$. It was A's associative value at the time of testing $X$, not A's associative value at the time of training $X$, that mattered. In its molarity, comparator theory was similar to contingency theory (Rescorla, 1967), a theory that attempted to predict behavior based on molar contingencies or correlations between CSs and USs, correlations calculated over long spans of time including multiple sessions. That view, however, was challenged by the fact that different groups of rats could receive molar correlations of zero and yet respond to the CS or not at the time of testing depending on the molecular details of trial sequencing at the time of training (Ayres, Benedict, \& Witcher, 1975; Benedict \& Ayres, 1972). For explanation, such results appeared to require a theory such as the Rescorla-Wagner model, in which the molecular ordering of trial types was crucially important.

In their recent paper, Blaisdell et al. (1999) have reaffirmed the importance of trial-sequence effects. They have found that, for blocking to occur, it is not sufficient that the rat receive $12 \mathrm{~A}+$ trials and $4 \mathrm{AX}+$ trials; rather, the two trial types must occur in a particular order (cf. Kamin, 1968). Specifically, at least two A+ trials must precede the first $\mathrm{AX}+$ trial. This must mean that something happening at the time of training, not just at the time of testing, is responsible for cue competition. It is exactly the result that learning-deficit theories such as the Rescorla-Wagner model anticipate. That model would hold, for example, that A's early acquisition of as- 
sociative value enables $A$ to win out over $X$ in the competition for the remaining associative value that the US can support and thus limits the amount of associative value that $\mathrm{X}$ can acquire. As comparator theorists, however, Blaisdell et al. (1999) reject that interpretation. Instead, they choose to say that the early reinforcement of A enables A to acquire "biological significance," which, in turn, limits the significance that $X$ can acquire. In their new version of comparator theory, performance at the time of testing $\mathrm{X}$ is now influenced not only by a comparison of the strengths of the X-US and A-US associations at the time of testing but also by the biological significance that $\mathrm{X}$ acquired at the time of training. The antecedent conditions for the construct of biological significance (Blaisdell et al., 1999, p. 67), however, appear to be remarkably similar to the antecedent conditions of the construct of associative value in the Rescorla-Wagner model. Both depend on the number of reinforced trials and the ordering of trial types during the training of CS X. In short, the distinction between comparator theory and learning-deficit theory is no longer as clear as it once was.

\section{Why the Discrepant Results Regarding Recovery From Cue Competition?}

As mentioned in our introduction, many studies have found no effect of reducing CS A's excitatory strength following $\mathrm{AX}+$ training in cue-competition procedures (Kamin, 1968; Rauhut et al., 1999; Revusky et al., 1977; Schachtman et al., 1992, Experiments 1, 2, and 3; the present experiments). At the same time, many other studies have indeed found the kinds of effects that are predicted by performance-deficit theories (Blaisdell et al., 1999; Cole et al., 1995; Harris \& Westbrook, 1998; Kaufman \& Bolles, 1981; Matzel et al., 1985, 1987; Yin et al., 1993). Still other studies have found the opposite effects (Couvillon \& Bitterman, 1982; Holland \& Ross, 1981; Rescorla \& Colwill, 1983; Schachtman et al., 1992, Experiments 4 and 5; Schweitzer \& Green, 1982; Speers et al., 1980).

What is responsible for these three different outcomes? Harris and Westbrook (1998) have presented an analysis that may give the appearance of enabling comparator theory to explain them. These authors suggest that extinguishing A following conditioning of the $\mathrm{AX}$ compound can weaken, enhance, or have no effect on the response to $\mathrm{X}$, depending on the strength of the within-compound association between $\mathrm{X}$ and $\mathrm{A}$. According to their analysis, there are two opposing factors: (1) the tendency for extinguishing CS A to cause retroactive revaluation of the X-US association (enhancement of the CR to $\mathrm{X}$ by weakening the comparator A-US association), and (2) the tendency of CS X to "borrow" strength from CS A because of X's association with $A$. That is, $X$ evokes a strong CR partly because it evokes a representation of its withincompound associate, $\mathrm{A}$; and $\mathrm{A}$, in turn, evokes its associated US representation. If the within-compound association is strong, then extinguishing $A$ can weaken the response to X (as in Couvillon \& Bitterman, 1982; Hol- land \& Ross, 1981; Schachtman et al., 1992, Experiments 4 and 5; Schweitzer \& Green, 1982; Speers et al., 1980) because the extinction robs $\mathrm{X}$ of its ability to borrow from $A$. If the within-compound association is moderately strong and $\mathrm{A}$ is extinguished, then the tendency for $\mathrm{X}$ to borrow from $\mathrm{A}$ can be offset by the retroactive revaluation tendency, meaning that extinguishing $A$ can have no effect on the response to X (as in Kamin, 1968; Rauhut et al., 1999; Revusky et al., 1977; Schachtman et al., 1992, Experiments 1, 2, and 3; present experiments). Finally, if the within-compound association is weak, $X$ cannot borrow from $\mathrm{A}$; therefore, extinguishing $\mathrm{A}$ can only cause retroactive revaluation. This would lead to an increase in the response to X (as in Blaisdell et al., 1999; Cole et al., 1995; Harris \& Westbrook, 1998; Kaufman \& Bolles, 1981; Matzel et al., 1985, 1987; Yin et al., 1993).

One should note, however, that the idea of $X$ "borrowing" strength from A is fundamentally incompatible with the assumptions of comparator theory. According to comparator theory, the response to $\mathrm{X}$ is inversely related to the product of the within-compound association and the strength of the A-US association. Those two things together prevent the expression of the X-US association (Blaisdell et al., 1999). Therefore, extinguishing either the within-compound association or the A-US association can only enhance, not weaken, the response to X.

Harris and Westbrook's (1998) emphasis on the importance of the strength of the within-compound association may be entirely correct (see Dickinson \& Burke, 1996); however, it is difficult to evaluate because, at present, we have no ways of measuring in nonhuman animals the strength of within-compound associations that are independent of the effects that the different strengths are invoked to explain.

Another approach to trying to explain the discrepancies in the literature is to make direct comparisons between the procedures used (and the results found) in the experiments that produced the three possible outcomes. Unfortunately, we find such comparisons to be of little help because the experiments differed in so many ways. Even if we confine our attention to studies that used the conditioned suppression method, comparisons are frustrated by major variations in that method. For example, studies that have supported performance-deficit theories have used a lick-suppression technique. In contrast, the present work and that of Kamin (1968), Rauhut et al. (1999), and Schweitzer and Green (1982), which did not support those theories, used a barpress-suppression technique. It seems unlikely to us that the difference between lick suppression and barpress suppression per se could be responsible for the discrepant results in the literature. Both forms of suppression appear to be mediated by the fear-induced evocation of defensive immobility (Albert \& Ayres, 1997; Bevins \& Ayres, 1992, 1994; Bouton \& Bolles, 1980; Mast et al., 1982; van Willigen, Emmett, Cote, \& Ayres, 1987). What does seem important to us, however, is the fact that those who have used the licksuppression technique either have not recorded any data 
prior to the posttreatment test or have not described those data. This is despite the fact that their experiments, like our own, involved multiple stages prior to the posttreatment test. This lack of data prior to posttreatment testing raises four major problems for any attempt to evaluate the lick-suppression work, much less to compare it with the barpress-suppression work of the present type.

First, if no data are recorded or described prior to the posttreatment test, it is impossible to see how well groups are matched on responding to the target cue prior to treatment designed to produce recovery from cue competition. Second, it is impossible to use the data leading to the posttreatment test to make inferences about learning processes occurring prior to that test. Third, it is impossible to compare the results leading to the posttreatment test with the results obtained in studies like the present one in which behavior was measured and described at each step before the final test. Fourth, it is impossible to corroborate the posttreatment test results with the results of measurements made before and after treatment. Thus, we would like to have a measure of the CR to the target cue both before and after a treatment intended to strengthen that $\mathrm{CR}$. The most persuasive evidence for recovery from cue competition would be the demonstration that the CR to the target cue did in fact increase within the treatment group from before to after treatment and that, after treatment, it was greater in the treatment group than in control groups.

Such before-versus-after comparisons can be made in the present work by comparing the X-probe test results with the final performance to $\mathrm{X}$ after intervening treatment (e.g., top panel of Figure 2 vs. Figure 4; top panel of Figure 5 vs. Figure 7). These comparisons show clearly that the intervening treatment $(\mathrm{B}+, \mathrm{BA}-$ training) did not enhance suppression to the target cue, $\mathrm{X}$, within the $\mathrm{CC} \_\mathrm{CI}$ condition. They agree with the between-groups, posttreatment comparisons.

Agreement between posttreatment and before-versusafter-treatment comparisons is not trivial. For example, strong evidence for recovery from cue competition is thought to exist in the literature on causal attribution in human subjects (e.g., Wasserman \& Berglan, 1998). Wasserman and Berglan argued that their evidence was particularly compelling. Using a completely within-subjects design, their method allowed posttreatment comparisons of causal efficacy and comparisons of causal efficacy before and after a treatment designed to produce recovery from cue competition. Their posttreatment comparison provided strong evidence for such recovery; yet, their before-versus-after comparison did not. Thus, the judged causal efficacy of their target cue did not increase appreciably following devaluation of its within-compound associate (compare means to Cue $\mathrm{Y}$ in Rating Periods 2 and 3 in their Table 3). So, did recovery from cue competition occur in their study or not? The results seem ambiguous. Given that the lick-suppression work on recovery from cue competition has described only the posttreat- ment behavior, we have no way of knowing whether a similar ambiguity might exist in that work.

Another factor that has been confounded with the differences in the lick-suppression versus barpresssuppression techniques is the duration of the CSs used. Studies using barpress-suppression techniques have used long CS durations ( $30 \mathrm{sec}$ to $3 \mathrm{~min}$ ), whereas those using lick-suppression have used short CS durations (usually $10 \mathrm{sec}$ ). As part of his doctoral dissertation, Rauhut (1999) performed a study that used the barpresssuppression techniques of the present work but with short (10-sec) CS durations. He found that A-trials given after $\mathrm{AX}+$ training weakened, not strengthened, the $\mathrm{CR}$ to $\mathrm{X}$. However, his results were inconclusive because, with short CSs, he was unable to find any evidence of cue competition. Thus, the importance of CS duration on recovery from cue competition within the conditioned suppression procedure remains unclear and should be further investigated.

\section{REFERENCES}

Albert, M., \& Ayres, J. J. B. (1997). One-trial simultaneous and backward excitatory fear conditioning in rats: Lick suppression, freezing, and rearing to $\mathrm{CS}$ compounds and their elements. Animal Learning \& Behavior, 25, 210-220.

AnNAU, Z., \& Kamin, L. J. (1961). The conditioned emotional response as a function of intensity of the US. Journal of Comparative \& Physiological Psychology, 54, 428-432.

Ayres, J. J. B., Benedict, J. O., \& Witcher, E. S. (1975). Systematic manipulation of individual events in a truly random control in rats. Journal of Comparative \& Physiological Psychology, 88, 97-103.

Balaz, M. A., Gutsin, P., Cacheiro, R., \& Miller, R. R. (1982). Blocking as a retrieval failure: Reactivation of associations to a blocked stimulus. Quarterly Journal of Experimental Psychology, 34B, 99-113.

BENEDICT, J. O., \& AYRES, J. J. B. (1972). Factors affecting conditioning in the truly random control procedure in the rat. Journal of Comparative \& Physiological Psychology, 78, 323-330.

Bevins, R. A., \& AYres, J. J. B. (1992). Rats' location during conditioned suppression training. Animal Learning \& Behavior, 20, 8-16.

Bevins, R. A., \& Ayres, J. J. B. (1994). Factors affecting rats' location during conditioned suppression training. Animal Learning $\&$ Behavior, 22, 302-308.

Blaisdell, A. P., Denniston, J. C., \& Miller, R. R. (1998). Temporal encoding as a determinant of overshadowing. Journal of Experimental Psychology: Animal Behavior Processes, 24, 72-83.

Blaisdell, A. P., Gunther, L. M., \& Miller, R. R. (1999). Recovery from blocking achieved by extinguishing the blocking CS. Animal Learning \& Behavior, 27, 63-76.

Bouton, M. E., \& Bolles, R. C. (1980). Conditioned fear assessed by freezing and by the suppression of three different baselines. Animal Learning \& Behavior, 8, 429-434.

Cole, R. P., Barnet, R. C., \& Miller, R. R. (1995). Effect of relative stimulus validity: Learning or performance deficit? Journal of Experimental Psychology: Animal Behavior Processes, 21, 293-303.

Couvillon, P. A., \& Bitterman, M. E. (1982). Compound conditioning in honeybees. Journal of Comparative \& Physiological Psychology, 96, 192-199.

DEVITO, P. L., \& FowLER, H. (1986). Effects of contingency violations on the extinction of a conditioned fear inhibitor and a conditioned excitor. Journal of Experimental Psychology: Animal Behavior Processes, 12, 99-115.

DEVITO, P. L., \& Fowler, H. (1987). Enhancement of conditioned inhibition via an extinction treatment. Animal Learning \& Behavior, $15,448-454$. 
Dickinson, A., \& Burke, J. (1996). Within-compound associations mediate the retrospective revaluation of causality judgments. Quarterly Journal of Experimental Psychology, 49B, 60-80.

Estes, W. K., \& SKINNER, B. F. (1941). Some quantitative properties of anxiety. Journal of Experimental Psychology, 29, 390-400.

HaRRIS, J. A., \& WESTBROOK, R. F. (1998). Retroactive revaluation of an odor-taste association. Animal Learning \& Behavior, 26, 326-335.

Holland, P. C., \& Ross, R. T. (1981). Within-compound associations in serial compound conditioning. Journal of Experimental Psychology: Animal Behavior Processes, 7, 228-241.

KAMIN, L. J. (1968). "Attention-like" processes in classical conditioning. In M. R. Jones (Ed.), Miami Symposium on the Prediction of Behavior, 1967: Aversive stimulation (pp. 9-31). Coral Gables, FL: University of Miami Press.

Kasprow, W. J., Cacheiro, H., Balaz, M., \& Miller, R. R. (1982). Reminder-induced recovery of associations to an overshadowed stimulus. Learning \& Motivation, 13, 155-166.

KaUfman, M. A., \& Bolles, R. C. (1981). A nonassociative aspect of overshadowing. Bulletin of the Psychonomic Society, 18, 318-320.

Mackintosh, N. J. (1975). A theory of attention: Variations in the associability of stimuli with reinforcement. Psychological Review, $\mathbf{8 2}$, 276-298.

Mast, M., Blanchard, R. J., \& Blanchard, D. C. (1982). The relationship of freezing and response suppression in a CER situation. Psychological Record, 32, 151-167.

Matzel, L. D., Schachtman, T. R., \& MilleR, R. R. (1985). Recovery of an overshadowed association achieved by extinction of the overshadowing stimulus. Learning \& Motivation, 16, 398-412.

Matzel, L. D., Shuster, K., \& Miller, R. R. (1987). Covariation in conditioned response strength between stimuli trained in compound. Animal Learning \& Behavior, 15, 439-447.

Miller, R. R., \& Grahame, N. J. (1991). Expression of learning. In L. Dachowski \& C. F. Flaherty (Eds.), Current topics in animal learning. Brain, emotion, and cognition (pp. 95-117). Hillsdale, NJ: Erlbaum

Miller, R. R., \& SchachTMan; T. R. (1985). Conditioning context as an associative baseline: Implications for response generation and the nature of conditioned inhibition. In R. R. Miller \& N. E. Spear (Eds.), Information processing in animals: Conditioned inhibition (pp. 5188). Hillsdale, NJ: Erlbaum

Pavlov, I. P. (1927). Conditioned reflexes (G. V. Anrep, Trans.). London: Oxford University Press.

Pearce, J. M. (1987). A model for stimulus generalization in Pavlovian conditioning. Psychological Review, 94, 61-73.

Pearce, J. M., \& Hall, G. (1980). A model for Pavlovian learning: Variations in the effectiveness of conditioned but not of unconditioned stimuli. Psychological Review, 87, 532-552.

RaUHUT, A. S. (1999). A reanalysis of cue-competition effects in Pavlovian fear conditioning in rats: Implications for neuronal theories of learning and memory. Unpublished doctoral dissertation, University of Massachusetts, Amherst.

Rauhut, A. S., McPhee, J. E., \& Ayres, J. J. B. (1999). Blocked and overshadowed stimuli are weakened in their ability to serve as blockers and second-order reinforcers in Pavlovian fear conditioning. Journal of Experimental Psychology: Animal Behavior Processes, 25, 45-67.

ResCorla, R. A. (1967). Pavlovian conditioning and its proper control procedures. Psychological Review, 74, 71-80.

Rescorla, R. A. (1969). Pavlovian conditioned inhibition. Psychological Bulletin, 72, 77-94

RESCORLA, R. A. (1971). Summation and retardation tests of latent inhibition. Journal of Comparative \& Physiological Psychology, 75, 77-81.

Rescorla, R. A., \& ColwILl, R. M. (1983). Within-compound associations in unblocking. Journal of Experimental Psychology: Animal Behavior Processes, 9, 390-400.

Rescorla, R. A., \& Freberg, L. (1978). The extinction of withincompound flavor associations. Learning \& Motivation, 9, 411-427.
Rescorla, R. A., \& Wagner, A. R. (1972). A theory of Pavlovian conditioning: Variations in the effectiveness of reinforcement and nonreinforcement. In A. H. Black \& W. F. Prokasy (Eds.), Classical conditioning II: Current research and theory (pp. 64-99). New York: Appleton-Century-Crofts.

Revusky, S., Parker, L. A., \& CoOmbes, S. (1977). Flavor aversion learning: Extinction of the aversion to an interfering flavor after conditioning does not affect the aversion to the reference flavor. Behavioral Biology, 19, 503-508.

Schachtman, T. R., Kasprow, W. J., Meyer, R. C., Bourne, M. J., \& HART, J. A. (1992). Extinction of the overshadowing CS after overshadowing in conditioned taste aversion. Animal Learning \& Behavior, 20, 207-218.

SChWEITZER, L., \& GreEN, L. (1982). Reevaluation of things past: A test of the "retrospection hypothesis" using a CER procedure with rats. Pavlovian Journal of Biological Science, 17, 62-68.

SHIPLEY, R. H. (1974). Extinction of conditioned fear in rats as a function of several parameters of CS exposure. Journal of Comparative \& Physiological Psychology, 87, 699-707.

Speers, M. A., Gillan, D. J., \& Rescorla, R. A. (1980). Withincompound associations in a variety of compound conditioning procedures. Learning \& Motivation, 11, 135-149.

Van Hamme, L. J., \& Wasserman, E. A. (1994). Cue competition in causality judgments: The role of nonpresentation of compound stimulus elements. Learning \& Motivation, 25, 127-151.

van Willigen, F., Emmett, J., Cote, D., \& Ayres, J. J. B. (1987). CS modality effects in one-trial backward and forward excitatory conditioning as assessed by conditioned suppression of licking in rats. $A n-$ imal Learning \& Behavior, 15, 201-211.

WAGNER, A. R. (1981). SOP: A model of automatic memory processing in animal behavior. In N. E. Spear \& R. R. Miller (Eds.), Information processing in animals: Memory mechanisms (pp. 5-47). Hillsdale, NJ: Erlbaum.

WASSERman, E. A., \& Berglan, L. R. (1998). Backward blocking and recovery from overshadowing in human causal judgement: The role of within-compound associations. Quarterly Journal of Experimental Psychology, 51 B, 121-138.

WINER, B. J. (1962). Statistical principles in experimental design. New York: McGraw-Hill.

Witcher, E. S., \& AYres, J. J. B. (1984). A test of two methods for extinguishing Pavlovian conditioned inhibition. Animal Learning \& Behavior, 12, 149-156.

Yin, H., Grahame, N. J., \& Miller, R. R. (1993). Extinction of comparator stimuli during and after acquisition: Differential facilitative effects on Pavlovian responding. Learning \& Motivation, 24, $219-241$.

Zimmer-HaRT, C. L., \& Rescorla, R. A. (1974). Extinction of Pavlovian conditioned inhibition. Journal of Comparative \& Physiological Psychology, 86, 837-845.

\section{NOTES}

1. When the experimental group receives $\mathrm{A}+$ followed by $\mathrm{AX}+$ and the control group receives only $\mathrm{X}+$, the difference between groups in their response to $\mathrm{X}$ on test trials reflects both blocking and overshadowing in unknown proportions. We chose this procedure to maximize cue competition.

2. In Experiment 1, the percentage of trials in which suppression ratios had to be estimated in each stage of the experiment was as follows: $3.8 \%$ in Stage 1, 1.2\% in Stage 2, 1.6\% in Stage 3, and $0 \%$ in Stages 4 and 5. In Experiment 2, the percentages were 1.3\% in Stage 1, $0 \%$ in Stage 2, $0.4 \%$ in Stage 3, $0.5 \%$ in Stage 4, and $0 \%$ in Stages 5, 6, 7, and 8 .

(Manuscript received April 5, 1999; revision accepted for publication September 6,1999 .) 